Check for updates

Cite this: RSC Adv., 2017, 7, 49251

\title{
Theoretical study on homolytic B-B cleavages of diboron(4) compounds $\uparrow$
}

\author{
Jiaoyang Wang, Wenrui Zheng (D)* and Yuanyuan Zheng
}

The organic synthesis reactions of diboron(4) compounds in which B-B cleavage is involved can introduce a new set of boron-containing organic reagents that were proven to be very useful in many organic synthetic routes and can be regarded as ideal candidates for green chemistry. So it is very valuable and significant to understand one of the thermodynamic properties of the B-B bond, the strength of the $\mathrm{B}-\mathrm{B}$ bond, which can be measured by using the homolytic bond dissociation enthalpies (BDEs). To this end, the 34 B-B BDEs of diboron(4) compounds were calculated by theoretical methods including composite high-level $a b$ initio and density functional theory (DFT) methods. The results show that it is reasonable and reliable to regard the $34 \mathrm{~B}-\mathrm{B} B \mathrm{BD}$ averages of the five high-level methods including G3, G3B3, CBS-Q, CBS-QB3 and ROCBS-QB3 as the standard reference values and the SOGGA11- $X$ method provides the best accuracy with the smallest root mean square error (RMSE) of $4.4 \mathrm{~kJ} \mathrm{~mol}^{-1}$. Subsequently, the B-B BDEs of three types of diboron(4) compounds according to their different molecular symmetry were investigated in detail by using this method. The results indicate that the different substituents have different effects on B-B BDE values. Natural bond orbital (NBO) analysis and investigations of the ground-state effect (GE) and the radical-state effect ( $R E)$ as well as frontier orbital energy analysis were performed in order to further disclose the essence of corresponding BDE change patterns. In addition, in order to better understand the catalytic process involving $\mathrm{B}-\mathrm{B}$ cleavages by transitional-metal catalysts, the $\mathrm{Pt}-\mathrm{B}$ and $\mathrm{Cu}-\mathrm{B}$ BDE predictions after $\mathrm{B}-\mathrm{B}$ cleavage were also conducted at this level. The results demonstrate that the participation of transition metals such as $\mathrm{Pt}$ and $\mathrm{Cu}$ can make the $\mathrm{B}-\mathrm{B}$ cleavage much easier and the different substituents have different effects on the stability of transition metal boryl complexes.

\author{
Received 15th August 2017 \\ Accepted 14th October 2017 \\ DOI: $10.1039 / \mathrm{c} 7 \mathrm{ra09006d}$ \\ rsc.li/rsc-advances
}

$\mathrm{B}_{2}(\text { alkyl })_{n}, \mathrm{~B}_{2}(\mathrm{OR})_{4}$, etc. mainly include borylation reactions, ${ }^{\mathbf{4 - 1 1}}$ diboration reactions, ${ }^{\mathbf{1 2 - 1 8}}$ borylative cyclization reactions, ${ }^{19-21}$ borylative ring opening reactions, ${ }^{22-27}$ boracarboxylation reactions, ${ }^{28}$ hydroboration and carboboration reactions, ${ }^{29-32}$ etc. For instance, Miyaura et al. ${ }^{33,34}$ developed the borylation reactions using dialkoxyboranes or diboron(4) compounds, such as $\mathrm{B}_{2}$ cat $_{2}$ (ref. 35) (cat $=1,2-\mathrm{O}_{2} \mathrm{C}_{6} \mathrm{H}_{4}$ ), $\mathrm{B}_{2}$ pin $_{2}$ (ref. 36 and 37) (pin =1,2- $\mathrm{O}_{2} \mathrm{C}_{2} \mathrm{Me}_{4}$ ), and $\mathrm{B}_{2}$ neop 2 (ref. 38) $\left(\right.$ neop $\left.=\mathrm{OCH}_{2} \mathrm{CMe}_{2} \mathrm{CH}_{2} \mathrm{O}\right)$ with organic halides under the condition of using a palladium catalyst. Marder et al. ${ }^{39}$ reported the rhodium(I)-catalyzed diboration reaction of $E$ styryl boronate esters with $\mathrm{B}_{2} \mathrm{cat}_{2}$, in which the 1,1,1-triborylalkane is the dominant product. Ito and co-workers ${ }^{\mathbf{4 0}}$ introduced the copper-catalyzed borylative cyclization reaction of allylic phosphates with $\mathrm{B}_{2} \mathrm{pin}_{2}$, and the 3-membered ring products were obtained. Szabó et al. ${ }^{\mathbf{4 1}}$ studied the borylative ring opening reaction of substituted vinylcyclopropanes and vinyl aziridines with tetrahydroxydiboron catalyzed by palladium. Besides the above exemplified reactions catalyzed by the transitional-metal catalyst, there are also many researches on the reactions involving diboron(4)
College of Chemistry and Chemical Engineering, Shanghai University of Engineering Science, Shanghai 201620, China. E-mail: wrzheng@sues.edu.cn; Fax: +86 21 67791220; Tel: +862167791216

$\dagger$ Electronic supplementary information (ESI) available. See DOI: 10.1039/c7ra09006d 
compounds under the transition-metal-free condition, such as borylation reactions, ${ }^{10,11}$ diboration reactions ${ }^{16-18}$ and borylative ring opening reactions, ${ }^{25-27}$ etc.

Based on the quantities of experimental studies on the reactions involving diboron(4) compounds, it is found that the B-B cleavages of diboron(4) compounds, which are involved in the reactions, play an extremely important role. Therefore, it is momentous and necessary to understand the relevant thermodynamic properties of the B-B bonds. One of the thermodynamic properties, the strength of the B-B bond, can be measured by using the homolytic bond dissociation enthalpies (BDEs). Unfortunately, the experimental B-B BDE values of diboron(4) compounds are very scarce, probably due to the difficulty in obtaining boron radicals during the experimental BDE measurements. ${ }^{42}$ With the rapid development of quantum chemistry and computers, the BDE calculations of organic compounds can be performed well by theoretical methods, such as composite methods and DFT methods etc. ${ }^{\mathbf{4 3 - 4 8}}$ For the examples of the theoretical researches on BDEs of organoboron compounds, Rablen ${ }^{\mathbf{4 9}}$ used $a b$ initio molecular orbital calculations at the G-2 and CBS-4 levels to investigate the B-H BDEs in a series of donoracceptor complexes of borane, and the results showed excellent agreement with experimental data. In our previous work, the $\mathrm{C}-\mathrm{B}$ BDEs including $\mathrm{C}(\mathrm{sp})-\mathrm{B}, \mathrm{C}\left(\mathrm{sp}^{2}\right)-\mathrm{B}$ and $\mathrm{C}\left(\mathrm{sp}^{3}\right)-\mathrm{B}$ of organoboron compounds such as boronic acids, trifluoroborate salts, boronate esters, etc. were calculated, and the M06-HF method was found to perform the best with the highest precision (the root mean square error equals to only $\left.6.4 \mathrm{~kJ} \mathrm{~mol}^{-1}\right){ }^{50}$ The theoretical studies on B-B BDEs of organoboron compounds were rarely reported. For example, Ducati et al. ${ }^{51}$ used the BP86/TZ2P method to calculate the B-B BDEs of OCBBCO, $\mathrm{N}_{2} \mathrm{BBN}_{2}$ and $[\mathrm{OBBBBO}]^{2-}$, and the values are $625.7 \mathrm{~kJ} \mathrm{~mol}^{-1}, 606.5 \mathrm{~kJ} \mathrm{~mol}^{-1}$ and $346.9 \mathrm{~kJ} \mathrm{~mol}^{-1}$, separately. Sakaki et al. ${ }^{52}$ calculated the B-B BDEs of $\mathrm{BH}_{2}-$ $\mathrm{BH}_{2}$ and $\mathrm{B}(\mathrm{OH})_{2}-\mathrm{B}(\mathrm{OH})_{2}$ by using the MP4SDQ method and the values are $375.8 \mathrm{~kJ} \mathrm{~mol}^{-1}$ and $433.0 \mathrm{~kJ} \mathrm{~mol}^{-1}$, respectively.

In our present study, the B-B BDEs of diboron(4) compounds as well as the substituent effects were systematically investigated by using theoretical methods including composite highlevel $a b$ initio methods and a series of DFT methods, which are considered to be very beneficial to better understand the B-B cleavages of diboron(4) compounds in synthesis reactions and provide more valuable guidance for the later experimental researches.

\section{Theoretical calculation strategy and method}

\subsection{Computational strategy}

The B-B bond cleavage of diboron(4) compounds is shown in the following reaction. The enthalpy change of this reaction under the conditions of $1 \mathrm{~atm}$ and $298.15 \mathrm{~K}$ in the gas phase represents the homolytic bond dissociation enthalpy (BDE) of the B-B bond. ${ }^{53}$

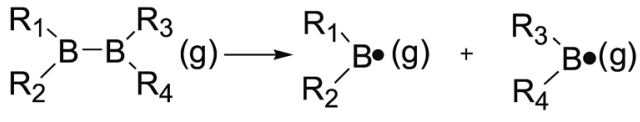

The enthalpy of each species can be calculated using the following equation:

$$
H(298 \mathrm{~K})=E+\mathrm{ZPE}+H_{\text {trans }}+H_{\text {rot }}+H_{\mathrm{vib}}+\mathrm{RT}
$$

In this equation, ZPE represents the zero point energy. The $H_{\text {trans }}, H_{\text {rot }}$, and $H_{\text {vib }}$ are the standard temperature correction terms calculated with equilibrium statistical mechanics with harmonic oscillator and rigid rotor approximations. ${ }^{54,55}$

\subsection{Computational method}

In our present study, the theoretical calculation methods including composite high-level ab initio methods and 28 DFT methods were used for B-B BDE calculations of diboron(4) compounds and all of the calculations were carried out with Gaussian 09 packages. ${ }^{56}$ In the composite high-level ab initio methods, the Gaussian-n (Gn) series $\left(\mathrm{G} 3,{ }^{57} \mathrm{G} 4,{ }^{58} \mathrm{G} 3 \mathrm{~B} 3{ }^{59,60}\right.$ G4MP2 (ref. 61)) and the complete-basis-set CBS series (CBS$4 \mathrm{M},{ }^{62,63}$ CBS-Q, ${ }^{64}$ CBS-QB3, ${ }^{65,66}$ ROCBS-QB3 (ref. 67)) which are suitable for the systems of less than 8 non-hydrogen atoms were selected. In addition, the 28 DFT methods including M06-HF, ${ }^{68} \mathrm{M} 05-2 \mathrm{X},{ }^{69} \mathrm{wB}^{2},{ }^{70} \mathrm{MN} 12-\mathrm{SX},{ }^{71} \mathrm{BMK},{ }^{72}$ SOGGA11-X, ${ }^{73}$ wB97XD, ${ }^{74} \mathrm{M} 06-2 \mathrm{X},{ }^{75} \mathrm{M} 06,{ }^{76} \mathrm{KMLYP},{ }^{77} \mathrm{MN} 12-$ $\mathrm{L}^{78} \mathrm{M} 11,{ }^{79} \mathrm{~N} 12-\mathrm{SX},{ }^{71} \mathrm{MPW} 1 \mathrm{~B} 95,{ }^{80}$ BP86-D3, ${ }^{81}$ MPW1P86, ${ }^{82}$ N12, ${ }^{83}$ B3P86, ${ }^{84}$ B3LYP-D3, ${ }^{85}$ M05, ${ }^{86}$ M06-L, ${ }^{87}$ CAM-B3LYP, ${ }^{88}$ PBE1PBE,${ }^{89}$ SOGGA11, ${ }^{90}$ MPW1K, ${ }^{91}$ B3LYP,${ }^{66}$ M11-L, ${ }^{92}$ B97D $^{93}$ were used. For the DFT calculations, the geometry optimizations and the frequency calculations of molecules and the corresponding radicals were performed at the B3LYP/6$31+G(d)$ level, which is suitable for structure optimization due to its high accuracy and lower computational cost.94-98 The basis set of $6-311++\mathrm{G}(2 \mathrm{df}, 2 \mathrm{p})$ was adopted for the singlepoint energy calculations. For the calculations of the transition metals $\mathrm{Pt}$ and $\mathrm{Cu}$, the effective core potential LANL2DZ basis set was used for the geometry optimizations and the SDD basis set was used for the single-point energy calculations.

\section{Results and discussion}

\subsection{The evaluation of composite high-level methods}

In view of the high computing resources demand of the composite high-level $a b$ initio methods which have high accuracy for the calculation of molecular energy, ${ }^{57,99-104}$ we designed 34 diboron(4) compounds including $\mathrm{B}_{2} \mathrm{X}_{4}, \mathrm{~B}_{2}\left(\mathrm{NR}_{2}\right)_{4}$, $\mathrm{B}_{2}(\text { alkyl })_{n}, \mathrm{~B}_{2}(\mathrm{OR})_{4}$, etc. in which less than 6 non-hydrogen atoms are included as the training set. In this training set, the experimental B-B BDE values of the 34 designed diboron(4) compounds are unknown. In order to better evaluate and compare the precisions of the different composite high-level ab initio methods, the Gaussian-n (Gn) 
Table 1 The 34 B-B BDEs of diboron(4) compounds calculated by 8 composite high-level methods $\left(\mathrm{kJ} \mathrm{mol}^{-1}\right)$

\begin{tabular}{|c|c|c|c|c|c|c|c|c|c|c|c|c|}
\hline \multirow[b]{2}{*}{ Entry } & \multirow[b]{2}{*}{ Molecules } & \multicolumn{4}{|c|}{ Gn series } & \multirow{2}{*}{$\begin{array}{l}\text { Average } \\
\text { values } \\
\text { (G3, G3B3) }\end{array}$} & \multicolumn{4}{|c|}{ CBS series } & \multirow{2}{*}{$\begin{array}{l}\text { Average values } \\
\text { (CBS-Q, CBS-QB3, } \\
\text { ROCBS-QB3) }\end{array}$} & \multirow{2}{*}{$\begin{array}{l}\text { Average values } \\
\text { (G3, G3B3, CBS-Q, } \\
\text { CBS-QB3, } \\
\text { ROCBS-QB3) }\end{array}$} \\
\hline & & G3 & G3B3 & G4 & G4MP2 & & CBS-Q & CBS-QB3 & ROCBS-QB3 & CBS-4M & & \\
\hline 1 & $\begin{array}{l}\mathrm{HO}_{1}^{\prime} \\
\mathrm{HO}^{\prime}-\mathrm{B}\end{array}$ & 434.4 & 433.8 & 423.3 & 416.9 & 434.1 & 433.5 & 433.4 & 433.4 & 427.2 & 433.4 & 433.7 \\
\hline 2 & $\begin{array}{l}\mathrm{HO} \\
\mathrm{HO}^{\prime}\end{array}$ & 414.8 & 413.8 & 404.0 & 398.4 & 414.3 & 414.8 & 414.0 & 414.0 & 405.7 & 414.3 & 414.3 \\
\hline 3 & $\begin{array}{l}\mathrm{HO} \\
\mathrm{HO}^{\prime}\end{array}$ & 406.9 & 405.8 & 398.0 & 392.9 & 406.4 & 407.2 & 406.5 & 406.5 & 399.9 & 406.7 & 406.6 \\
\hline 4 & $\mathrm{H}_{3} \mathrm{C}^{\prime}$ & 392.5 & 391.0 & 382.5 & 378.0 & 391.8 & 393.6 & 391.5 & 391.5 & 382.6 & 392.2 & 392.0 \\
\hline 5 & $\mathrm{H}_{3} \mathrm{C}^{\prime}$ & 394.4 & 393.0 & 385.9 & 381.6 & 393.7 & 396.0 & 393.9 & 393.9 & 388.1 & 394.6 & 394.2 \\
\hline 6 & $\mathrm{H}_{3} \mathrm{C}$ & 406.8 & 404.9 & 398.9 & 394.7 & 405.9 & 410.5 & 406.4 & 406.4 & 404.1 & 407.8 & 407.0 \\
\hline 7 & $\begin{array}{l}\mathrm{H}_{2} \mathrm{~N} \\
\mathrm{H}_{2} \mathrm{~N}^{\prime}\end{array}$ & 426.3 & 423.9 & 416.4 & 412.1 & 425.1 & 425.9 & 426.3 & 426.1 & 420.1 & 426.1 & 425.7 \\
\hline 8 & $\begin{array}{l}\mathrm{H}_{2} \mathrm{~N} \\
\mathrm{H}_{2} \mathrm{~N}^{\prime}\end{array}$ & 417.2 & 415.0 & 407.6 & 403.5 & 416.1 & 418.2 & 417.3 & 417.2 & 411.7 & 417.6 & 417.0 \\
\hline 9 & $\begin{array}{l}\mathrm{H}_{2} \mathrm{~N} \\
\mathrm{H}_{2} \mathrm{~N}^{\prime}\end{array}$ & 410.4 & 408.7 & 401.6 & 397.5 & 409.6 & 412.9 & 410.7 & 410.6 & 405.2 & 411.4 & 410.7 \\
\hline 10 & $\begin{array}{l}\mathrm{H}_{2} \mathrm{~N}^{\prime} \\
\mathrm{H}_{3} \mathrm{C}^{\prime}\end{array}$ & 408.9 & 406.9 & 399.7 & 395.7 & 407.9 & 410.7 & 409.0 & 408.9 & 404.3 & 409.5 & 408.9 \\
\hline 11 & $\begin{array}{l}\mathrm{H}_{2} \mathrm{~N} \\
\mathrm{H}_{3} \mathrm{C}^{\prime}\end{array}$ & 403.9 & 402.0 & 395.4 & 391.3 & 403.0 & 406.8 & 403.8 & 403.7 & 400.2 & 404.8 & 404.0 \\
\hline 12 & & 436.0 & 436.5 & 426.2 & 419.3 & 436.3 & 439.2 & 439.2 & 439.1 & 426.0 & 439.2 & 438.0 \\
\hline 13 & & 424.0 & 423.5 & 414.4 & 409.2 & 423.8 & 426.4 & 425.6 & 425.6 & 423.3 & 425.9 & 425.0 \\
\hline 14 & $\mathrm{HS}$ & 423.0 & 421.2 & 411.7 & 407.9 & 422.1 & 423.1 & 420.0 & 420.4 & 417.3 & 421.2 & 421.5 \\
\hline 15 & $\begin{array}{l}\text { HS } \\
H^{\prime}\end{array}$ & 419.2 & 417.7 & 409.7 & 405.7 & 418.5 & 421.0 & 418.1 & 418.4 & 415.9 & 419.2 & 418.9 \\
\hline 16 & $\begin{array}{l}\mathrm{HS} \\
\mathrm{HS}^{\prime}\end{array}$ & 414.9 & 412.6 & 405.4 & 401.1 & 413.8 & 417.2 & 413.2 & 413.3 & 410.7 & 414.6 & 414.2 \\
\hline 17 & & 415.8 & 414.0 & 407.3 & 403.4 & 414.9 & 418.4 & 415.3 & 415.5 & 413.5 & 416.4 & 415.8 \\
\hline
\end{tabular}


Table 1 (Contd.)

$\begin{array}{ll}\text { Gn series } & \begin{array}{l}\text { Average } \\ \text { values }\end{array}\end{array}$

Entry Molecules
CBS series
Average values (CBS-Q, CBS-Q ROCBS-QB3)
Average values

(G3, G3B3, CBS-Q, CBS-QB3, ROCBS-QB3)

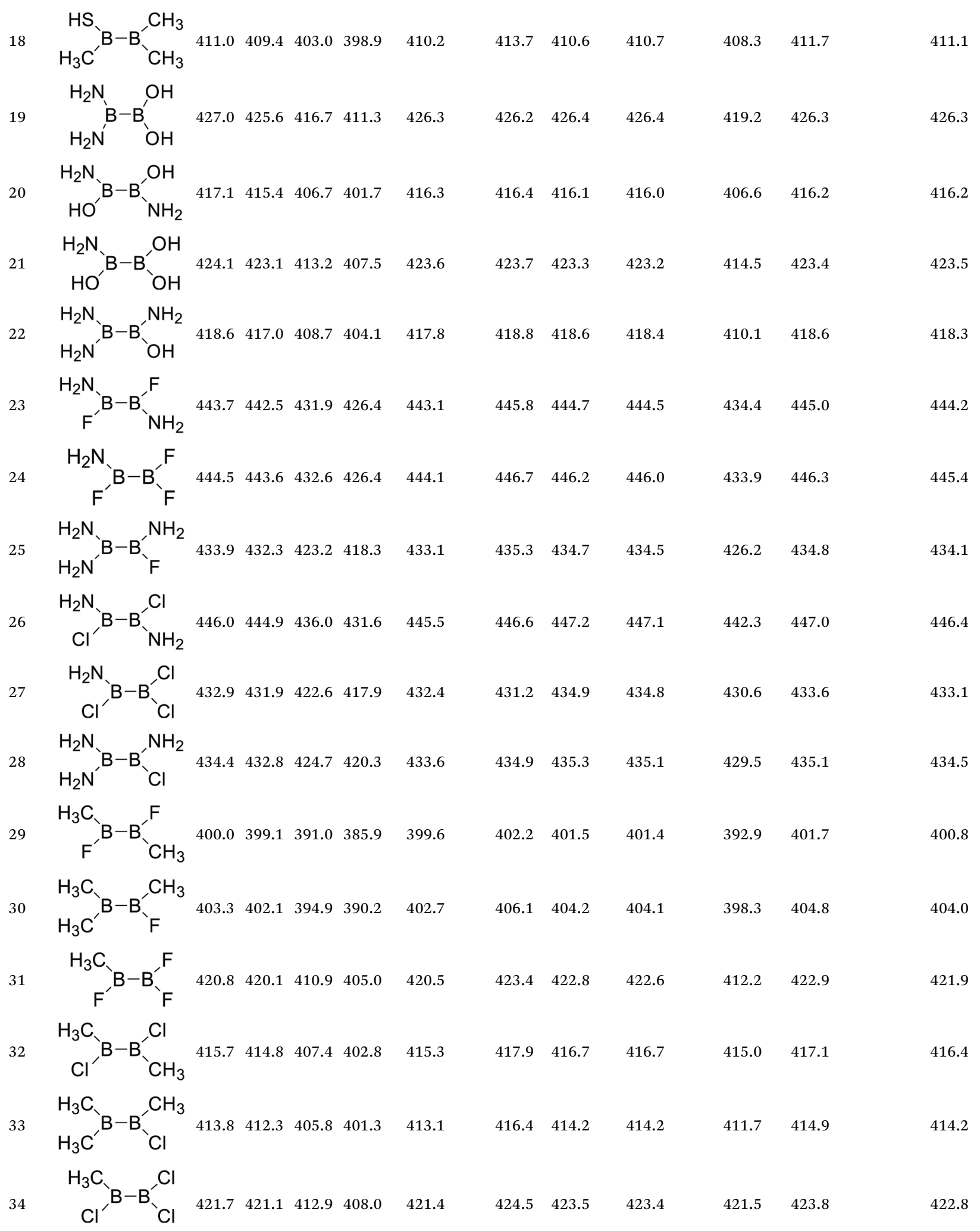




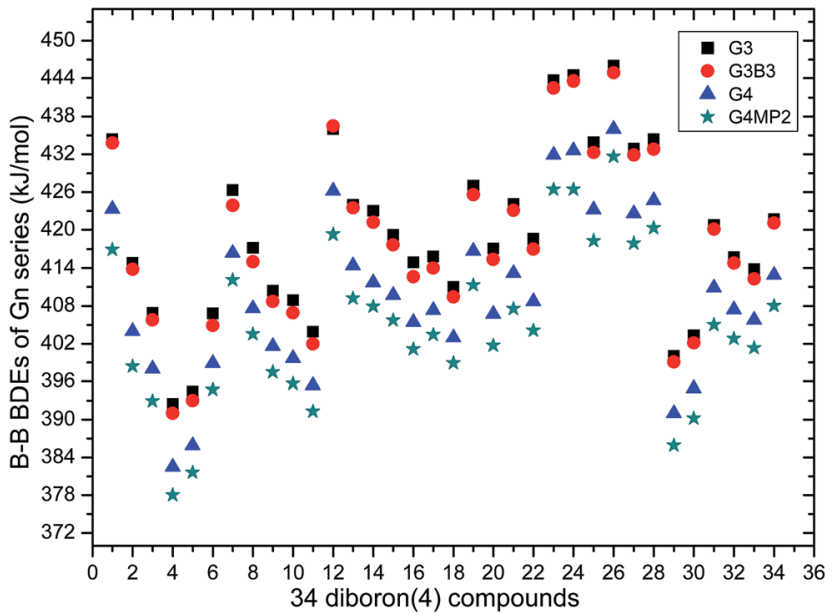

Fig. $134 \mathrm{~B}-\mathrm{B}$ BDE distributions of Gn series.

series (G3, G3B3, G4,G4MP2) as well as the complete-basisset CBS series (CBS-4M, CBS-Q, CBS-QB3, ROCBS-QB3) were used. The calculated B-B BDE values were listed in the Table 1. Moreover, the corresponding average values of B-B BDEs were also listed.

The 34 B-B BDE value distributions by the eight high-level methods were depicted in the following figures, in which the consistency of the eight methods including Gn and CBS series for B-B BDE calculations can be intuitively shown. In Fig. 1, the $34 \mathrm{~B}-\mathrm{B}$ BDE distributions of the Gn series were listed. It can be seen that the $34 \mathrm{~B}-\mathrm{B}$ BDEs calculated by G4 and G4MP2 are lower than those by G3 and G3B3, and the G4MP2 gave the smallest $34 \mathrm{~B}-\mathrm{B}$ BDEs. Moreover, there is a very good consistency between $\mathrm{G} 3$ and $\mathrm{G} 3 \mathrm{~B} 3$ values for all the $34 \mathrm{~B}-\mathrm{B}$ BDEs. Therefore, the $34 \mathrm{~B}-\mathrm{B}$ BDE average values of G3 and G3B3 methods were calculated. In Fig. 2, the 34 B-B BDE distributions of CBS series were depicted. Similarly, it is shown that the $34 \mathrm{~B}-\mathrm{B}$ BDE values calculated by CBS-Q, CBS-QB3 and ROCBS-QB3 are very close and the CBS$4 \mathrm{M}$ gives the smallest $34 \mathrm{~B}-\mathrm{B}$ BDE values. Due to the good

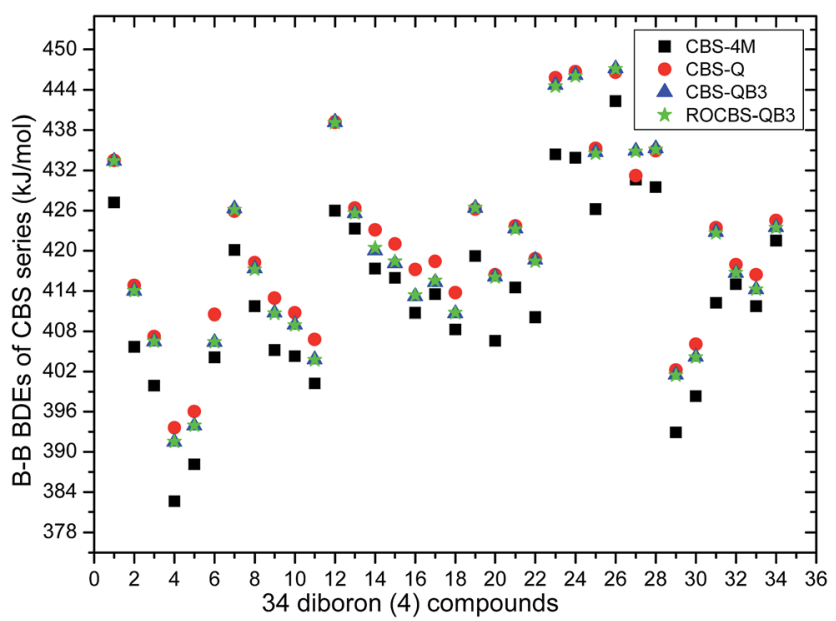

Fig. 234 B-B BDE distributions of CBS series.

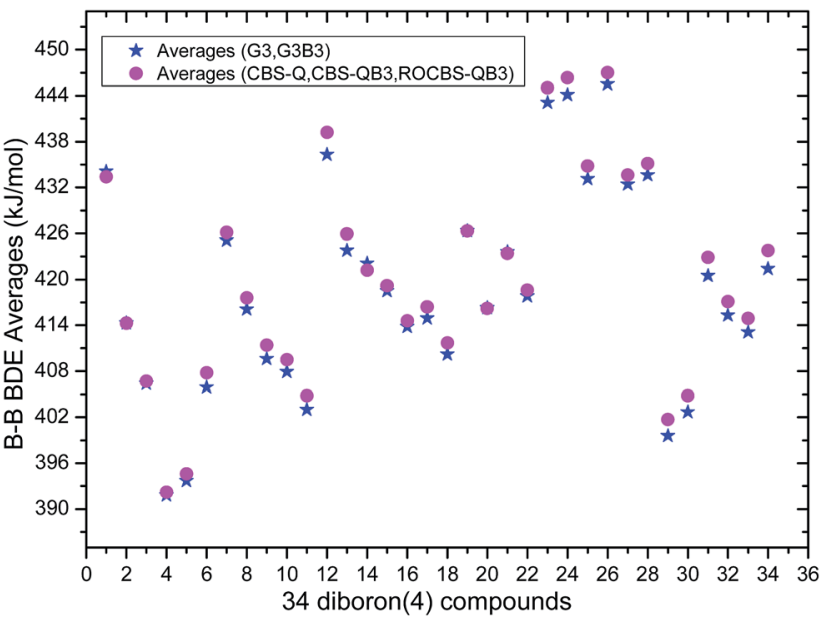

Fig. 334 B-B average BDE distributions of two series.

self-consistency between the CBS-Q, CBS-QB3 and ROCBSQB3 methods in CBS series for 34 B-B BDE calculations, the 34 average values of these three methods were calculated, which are listed in the Table 1 . Based on the above observations, the distributions of $34 \mathrm{~B}-\mathrm{B}$ BDE average values of Gn series (G3, G3B3) and CBS series (CBS-Q, CBS-QB3, ROCBS-QB3) were depicted in Fig. 3, which indicates that there is a good agreement between the two different highlevel method series. Furthermore, the good linear relationship between the $34 \mathrm{~B}-\mathrm{B}$ BDE averages of Gn and CBS series was shown in Fig. 4, and the correlation coefficient $(R)$ is high to 0.998 .

Overall, the 34 B-B BDE averages of the five high-level methods including G3, G3B3, CBS-Q, CBS-QB3 and ROCBSQB3 were calculated and listed in the Table 1. Considering that the 34 experimental B-B BDEs are unknown, it is reasonable and reliable to regard the $34 \mathrm{~B}-\mathrm{B}$ BDE averages of the five high-level methods as the standard reference values for the DFT methods evaluation in the subsequent study.

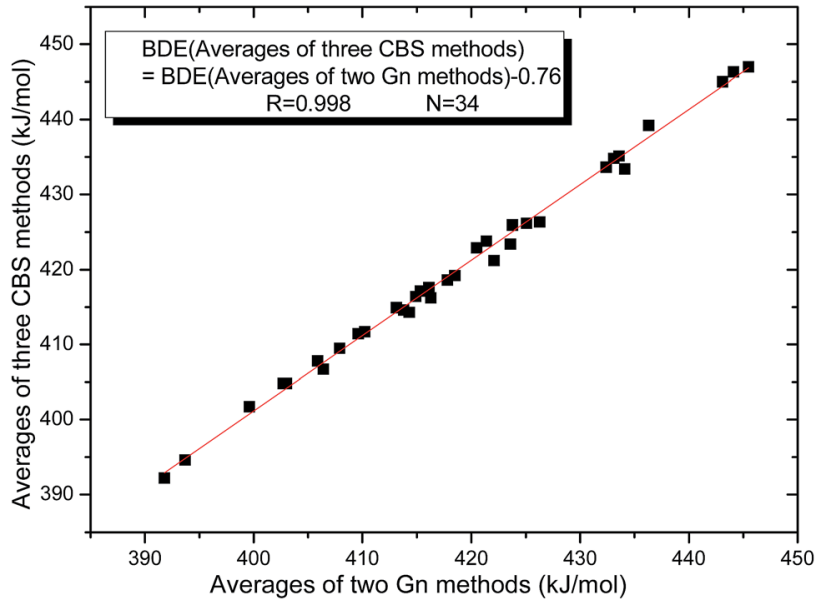

Fig. 4 Correlation between averages (Gn series) and averages (CBS series). 


\subsection{The evaluation of DFT methods}

For the B-B BDE calculations of the large systems, the composite high-level ab initio methods are not applicable. Currently, the density functional theory (DFT) method has been developed as a popular theoretical tool for the BDE calculations because of its relatively low CPU-costs, no serious spin-contamination and reasonable calculation precision. ${ }^{\mathbf{1 0 5 - 1 0 8}}$ In order to find out an economical and accurate method to predict the B-B BDEs of large diboron(4) compounds, the 28 DFT methods were selected to calculate the $34 \mathrm{~B}-\mathrm{B}$ BDEs in Table 1 and the corresponding results are listed in the ESI. $\dagger$ Among these DFT methods, there are some functionals with dispersion correction such as B3LYP-D3, B97D and long-range correction such as wB97XD, CAMB3LYP. The generalized gradient approximations (GGA) such as SOGGA11, the hybrid GGA such as MPW1K, SOGGA11-X, the meta-GGA like M06-L, M11-L, the globalhybrid meta-GGA such as MPW1B95, M05, M05-2X, M06, M06-2X, M06-HF and the range-separated hybrid meta-GGA like M11 as well as the nonseparable gradient approximation (NGA) like N12, the meta-NGA like MN12-L and the range-separated hybrid meta-NGA like MN12-SX were included. Furthermore, these functionals such as N12, M11, M11-L, MN12-L, MN12-SX, SOGGA11, SOGGA11-X were produced after 2010 .

By comparing the $34 \mathrm{~B}-\mathrm{B}$ BDEs calculated by the 28 DFT methods with the standard reference values, the corresponding mean deviation (MD), mean absolute deviation (MAD) and root mean square error (RMSE) values were listed in the Table 2. From this table, it can be seen that the SOGGA11-X method gives the highest precision for the $\mathrm{B}-\mathrm{B}$ BDE calculations, and the RMSE value is the smallest of $4.4 \mathrm{~kJ} \mathrm{~mol}^{-1}$. The MD, MAD values are $-1.8 \mathrm{~kJ} \mathrm{~mol}^{-1}$ and $3.3 \mathrm{~kJ} \mathrm{~mol}^{-1}$, respectively. In addition, the KMLYP method is the second better, and the corresponding RMSE, MD and MAD values are $6.3 \mathrm{~kJ} \mathrm{~mol}^{-1}, 5.4 \mathrm{~kJ} \mathrm{~mol}^{-1}$ and $5.4 \mathrm{~kJ} \mathrm{~mol}^{-1}$, separately. The M11-L method gives the worst accuracy,

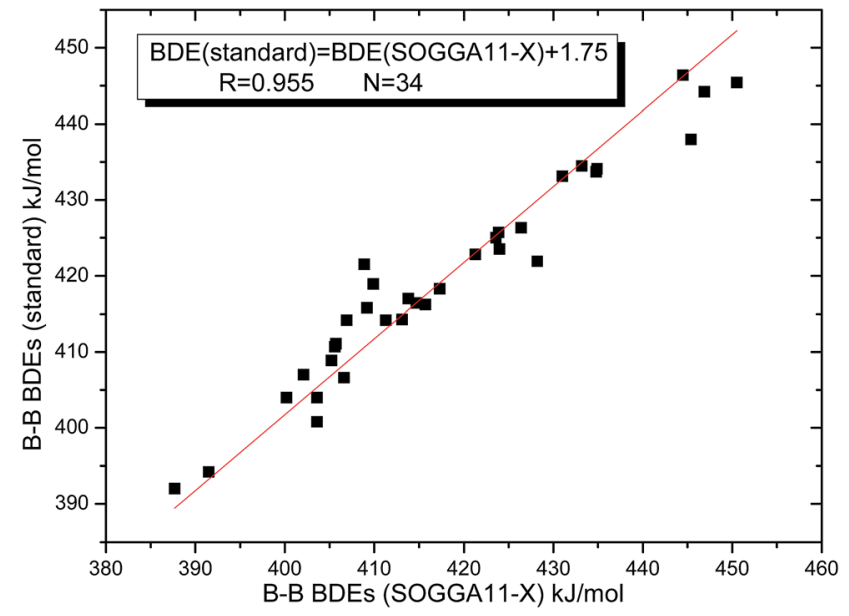

Fig. 5 Correlation between 34 B-B BDEs by SOGGA11-X and standard reference values.

because the RMSE value reaches to the highest of $51.5 \mathrm{~kJ} \mathrm{~mol}{ }^{-1}$, and the MD and MAD values are $-51.4 \mathrm{~kJ} \mathrm{~mol}^{-1}$ and $51.4 \mathrm{~kJ} \mathrm{~mol}^{-1}$. The B3LYP method, which is a relatively popular method, ${ }^{66}$ does not give high precision for the B-B BDE calculations, and the MD, MAD, RMSE values are $-34.5 \mathrm{~kJ} \mathrm{~mol}^{-1}, 34.5 \mathrm{~kJ} \mathrm{~mol}^{-1}$ and $34.6 \mathrm{~kJ} \mathrm{~mol}^{-1}$, respectively. The precisions of corresponding dispersion correction function and long-range correction function, i.e. B3LYP-D3 and CAM-B3LYP, have been improved a little as compared to the B3LYP. In addition, the wB97 method has a better precision than the long-range correction method wB97XD. The RMSE values of M06-HF, M06, M06-2X and M06-L methods are $9.0 \mathrm{~kJ} \mathrm{~mol}^{-1}, 13.4 \mathrm{~kJ} \mathrm{~mol}^{-1}, 20.1 \mathrm{~kJ} \mathrm{~mol}^{-1}$ and $27.9 \mathrm{~kJ} \mathrm{~mol}^{-1}$, in which the precision is gradually worse. Besides, some functionals that appeared after 2010 such as MN12-SX, MN12-L, M11, N12, SOGGA11 do not give good precision for the B-B BDE calculations. Subsequently, the

Table 2 Correlations between the 34 theoretical B-B BDEs by 28 DFT methods with the standard reference values $\left(\mathrm{kJ} \mathrm{mol}^{-1}\right)^{a}$

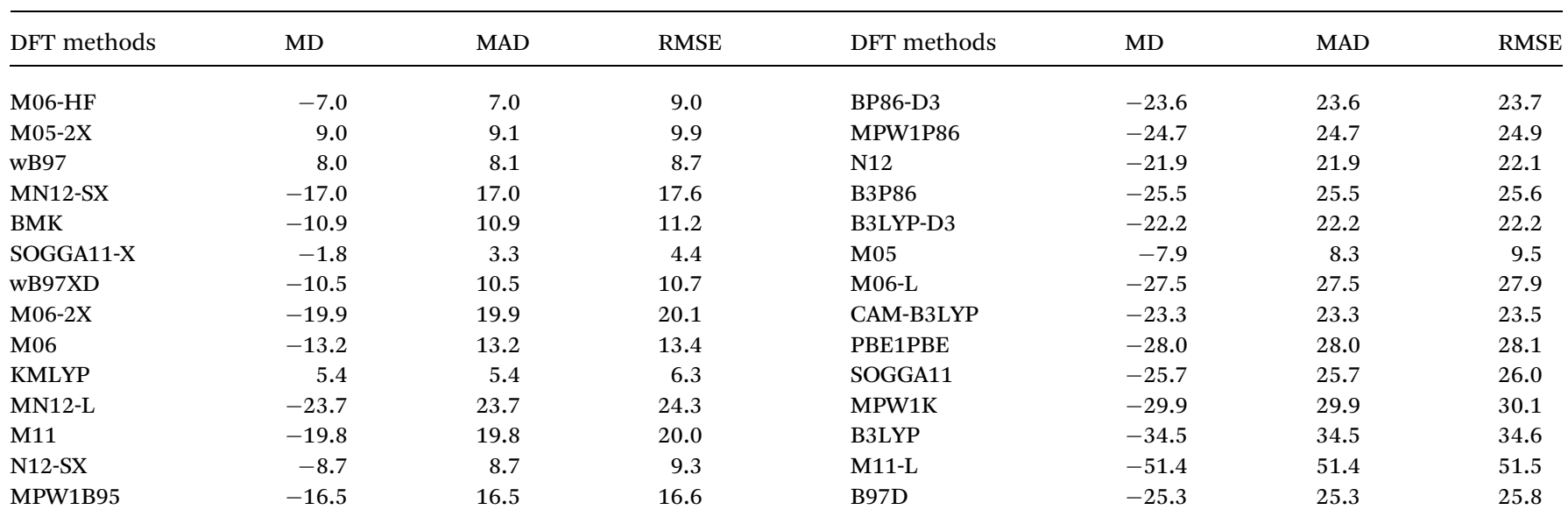

${ }^{a}$ Note: $\mathrm{MD}($ mean deviation $)=\sum\left(x_{i}-y_{i}\right) / N ; \operatorname{MAD}($ mean absolute deviation $)=\sum\left|x_{i}-y_{i}\right| / N ; \operatorname{RMSE}($ root mean square error $)=\left[\sum\left(x_{i}-y_{i}\right)^{2} / N\right]^{1 / 2}(N=$ $34, x_{i}$ represents the BDEs of DFT methods, and $y_{i}$ represents the standard reference values). 
good linear relationship between the $34 \mathrm{~B}-\mathrm{B}$ BDEs calculated by SOGGA11-X method and the standard reference values was depicted in Fig. 5, in which the correlation coefficient $(R)$ is 0.955. In view of the above analysis, the best method SOGGA11-X was used to investigate the B-B BDEs of large diboron(4) compounds in the following discussions.

\subsection{The B-B BDE predictions of diboron(4) compounds}

The B-B homolytic cleavage of diboron(4) compounds which are involved in quantities of reported reactions, can be mainly divided into three types described in the following according to the different molecular symmetry of the compounds. Herein, the $\mathrm{R}_{1}$ and $\mathrm{R}_{2}$ groups include $-\mathrm{X},-\mathrm{NR}_{2}$, -alkyl, -SR and -OR etc.

Table 3 The B-B BDEs, bond lengths, Wiberg bond orders, orbital energies as well as the GE and RE values of diboron(4) compounds in reaction (3)

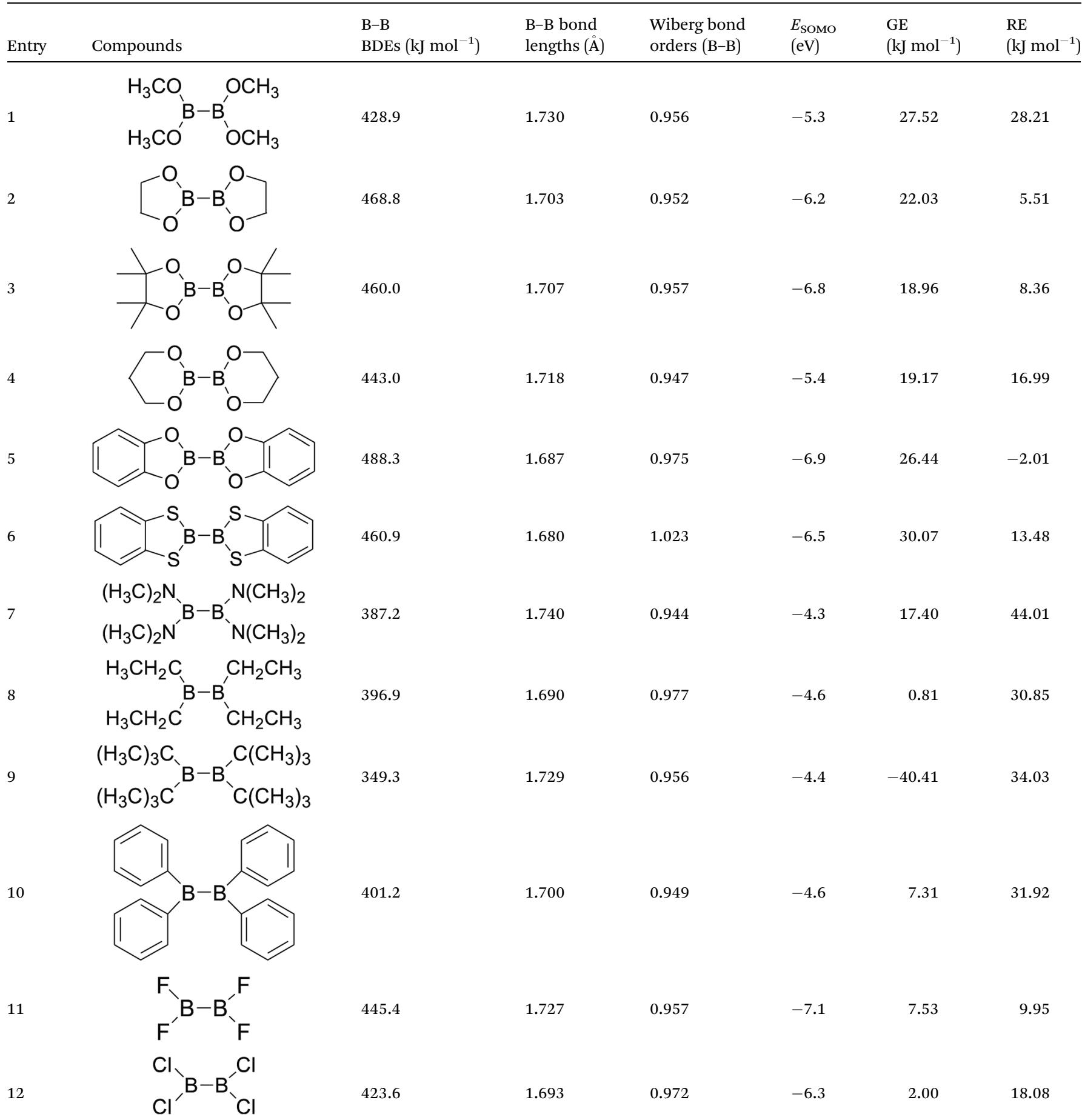




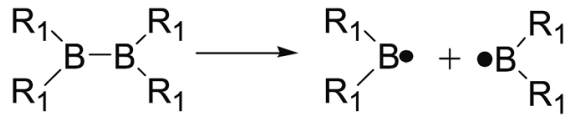<smiles>[R][B][B][B][R]</smiles>

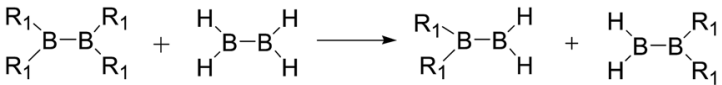

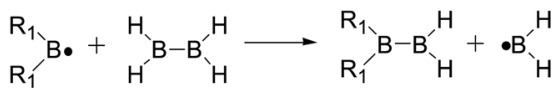

Scheme 1 GE (a) and RE (b) of these diboron(4) compounds in reaction (3).

conformation difference may lead to the B-B BDE difference between them. For the $\mathrm{B}_{2}\left(\mathrm{NR}_{2}\right)_{4}$ and $\mathrm{B}_{2}(\text { alkyl })_{4}$ compounds (Entries 7-10), the B-B BDEs were $387.2 \mathrm{~kJ} \mathrm{~mol}^{-1}$, $396.9 \mathrm{~kJ} \mathrm{~mol}^{-1}, 349.3 \mathrm{~kJ} \mathrm{~mol}^{-1}$ and $401.2 \mathrm{~kJ} \mathrm{~mol}^{-1}$, respectively, which are obviously lower than other $\mathrm{R}_{1}$ groups including -OR, -SR, etc. Especially, the B-B BDE of $\mathrm{B}_{2}\left(\mathrm{C}\left(\mathrm{CH}_{3}\right)_{3}\right)_{4}$ (Entry 9) is the lowest in all of the diboron(4) compounds. In addition, for the $\mathrm{B}_{2} \mathrm{X}_{4}$ compounds, the convenient solution-phase syntheses of $\mathrm{B}_{2} \mathrm{~F}_{4}, \mathrm{~B}_{2} \mathrm{Cl}_{4}$ and $\mathrm{B}_{2} \mathrm{I}_{4}$ from the common precursor $\mathrm{B}_{2} \mathrm{Br}_{4}$ were proposed by Braunschweig et al. in the recent study. ${ }^{109}$ In our calculations, the B-B BDE of $\mathrm{B}_{2} \mathrm{~F}_{4}$ (Entry 11) is higher than $\mathrm{B}_{2} \mathrm{Cl}_{4}$ (Entry 12), and the difference between them is $21.8 \mathrm{~kJ} \mathrm{~mol}^{-1}$, which shows that the more electronegative halides make the $\mathrm{B}-\mathrm{B}$ bond stronger. Similarly, there is a large conformation difference between $\mathrm{B}_{2} \mathrm{~F}_{4}$ and $\mathrm{B}_{2} \mathrm{Cl}_{4}$ (Fig. 6), that is, the $\mathrm{B}_{2} \mathrm{~F}_{4}$ is plane conformation, while the $\mathrm{B}_{2} \mathrm{Cl}_{4}$ is perpendicular, which is in accordance with the results of Demachy et al. ${ }^{110}$ From above analysis, it is found that the different $R_{1}$ groups including $-\mathrm{X},-\mathrm{NR}_{2},-$ alkyl, $-\mathrm{SR}$ and $-\mathrm{OR}$, etc. have great effects on the B-B BDE values. Besides, the B-B bond lengths and the Wiberg bond orders of $\mathrm{B}-\mathrm{B}$ bond were listed in Table 3. It can be seen that the range of $B-B$ bond lengths is from $1.680 \AA$ to $1.740 \AA$, and the Wiberg bond orders of B-B bond are around 1.000 for all of the diboron(4) compounds.

Usually, in order to better investigate the substituent effects on BDEs, the $\beta$-substituent effects can be separated into the ground-state effect (GE) and the radical-state effect
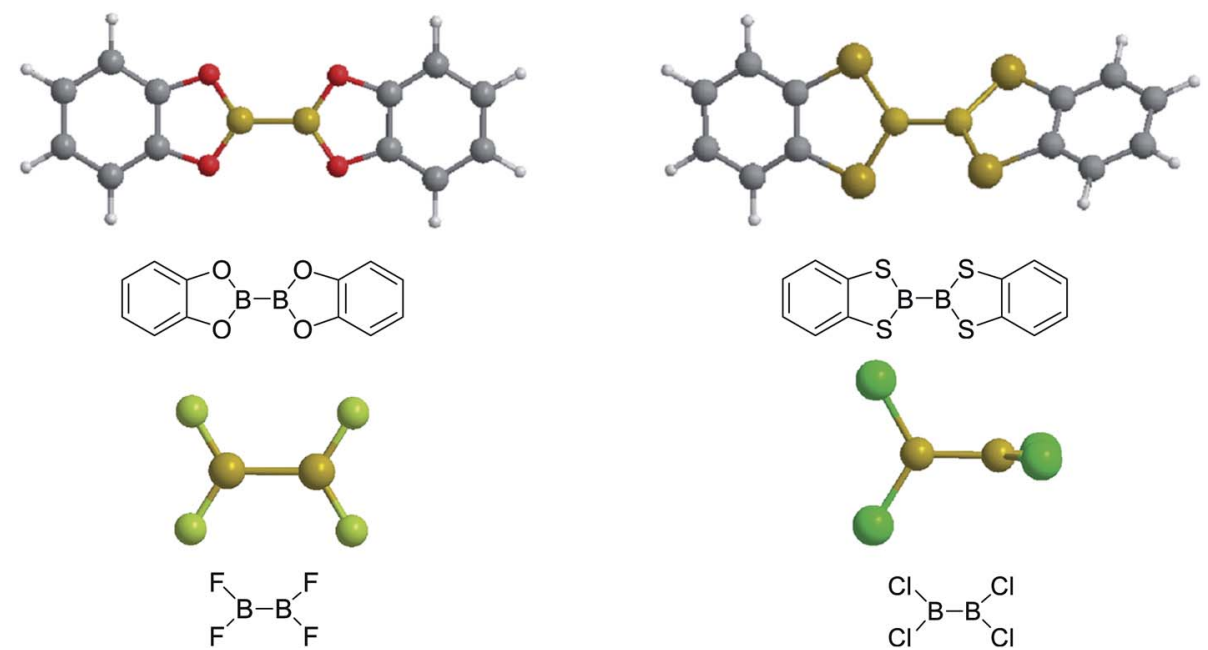

Fig. 6 The molecular optimized conformations at the B3LYP/6-31+G(d) level of four diboron(4) compounds in reaction (3). 
(RE). ${ }^{55,111-113}$ As a reference, the $\mathrm{R}_{1}$ effects on B-B BDEs in our system can similarly be divided into GE and RE defined by the enthalpy changes of the reactions (a) and (b) in Scheme 1, and the GE and RE values calculated by the SOGGA11-X method are shown in the Table 3. Generally speaking, the positive GE (RE) values indicate that the stability of the molecules (radicals) is enhanced while the negative values represent the stability of the molecules (radicals) is weakened by the substituents, and the overall effects determine the change pattern of the B-B BDEs. From the Table 3, it can be seen that for the $\mathrm{B}_{2}\left(\mathrm{C}\left(\mathrm{CH}_{3}\right)_{3}\right)_{4}$ (Entry 9 ) with the smallest B-B $\mathrm{BDE}$ value of $349.3 \mathrm{~kJ} \mathrm{~mol}^{-1}$, the GE value is a larger absolute negative value $\left(-40.41 \mathrm{~kJ} \mathrm{~mol}^{-1}\right)$ while the $\mathrm{RE}$ value is a larger positive value $\left(34.03 \mathrm{~kJ} \mathrm{~mol}^{-1}\right)$, which indicates that the

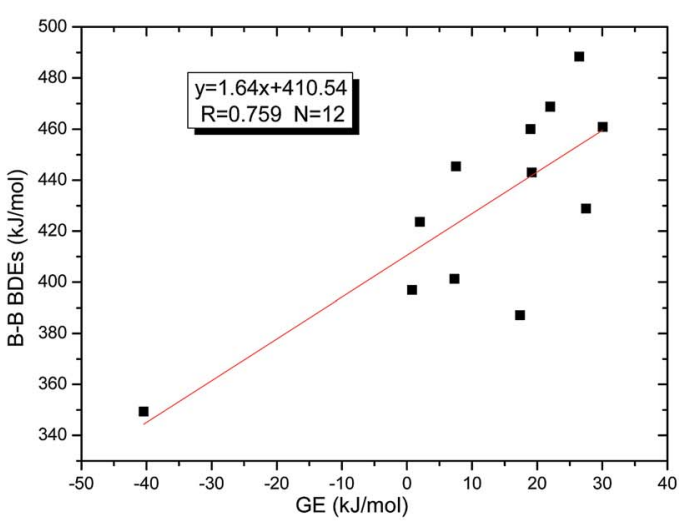

(a)

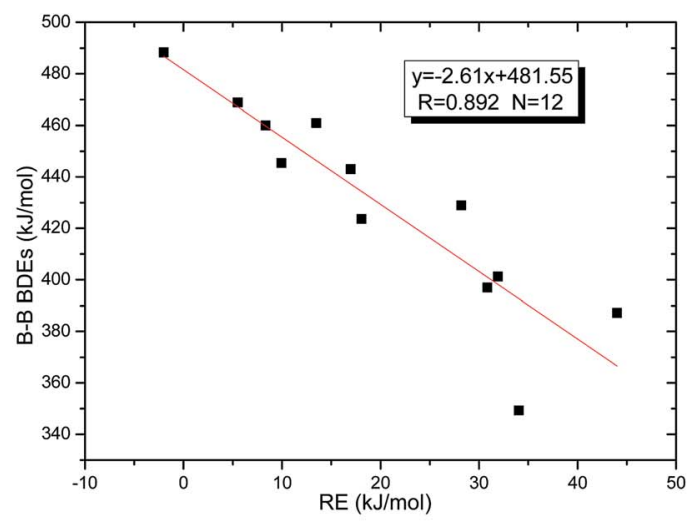

(b)

Fig. 7 (a) Correlation between GE values with B-B BDEs. (b) Correlation between RE values with B-B BDEs.

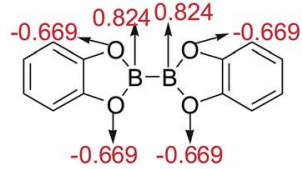

488.3

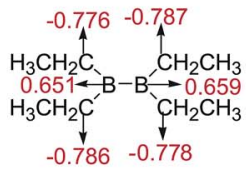

B-B BDEs $(\mathrm{kJ} / \mathrm{mol})$

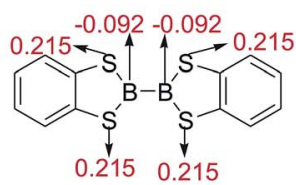

460.9

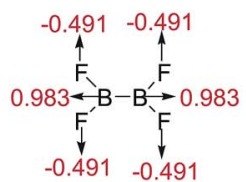

445.4

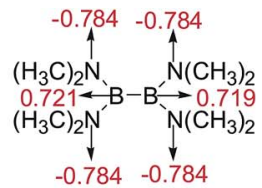

387.2

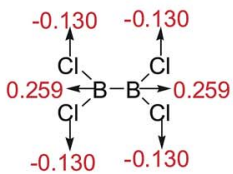

423.6

Fig. 8 Natural charges of atoms in molecules of representative diboron(4) compounds.
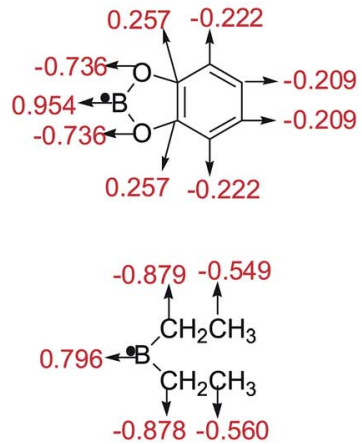
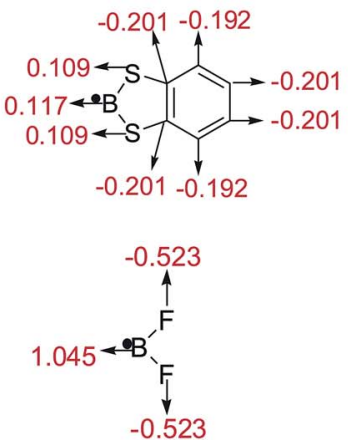
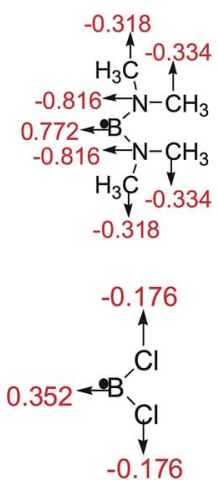

Fig. 9 Natural charges of atoms in radicals after B-B cleavage of diboron(4) compounds. 
Table 4 The B-B BDEs as well as the GE and RE values of diboron(4) compounds in reaction (4) (kJ mol ${ }^{-1}$ )

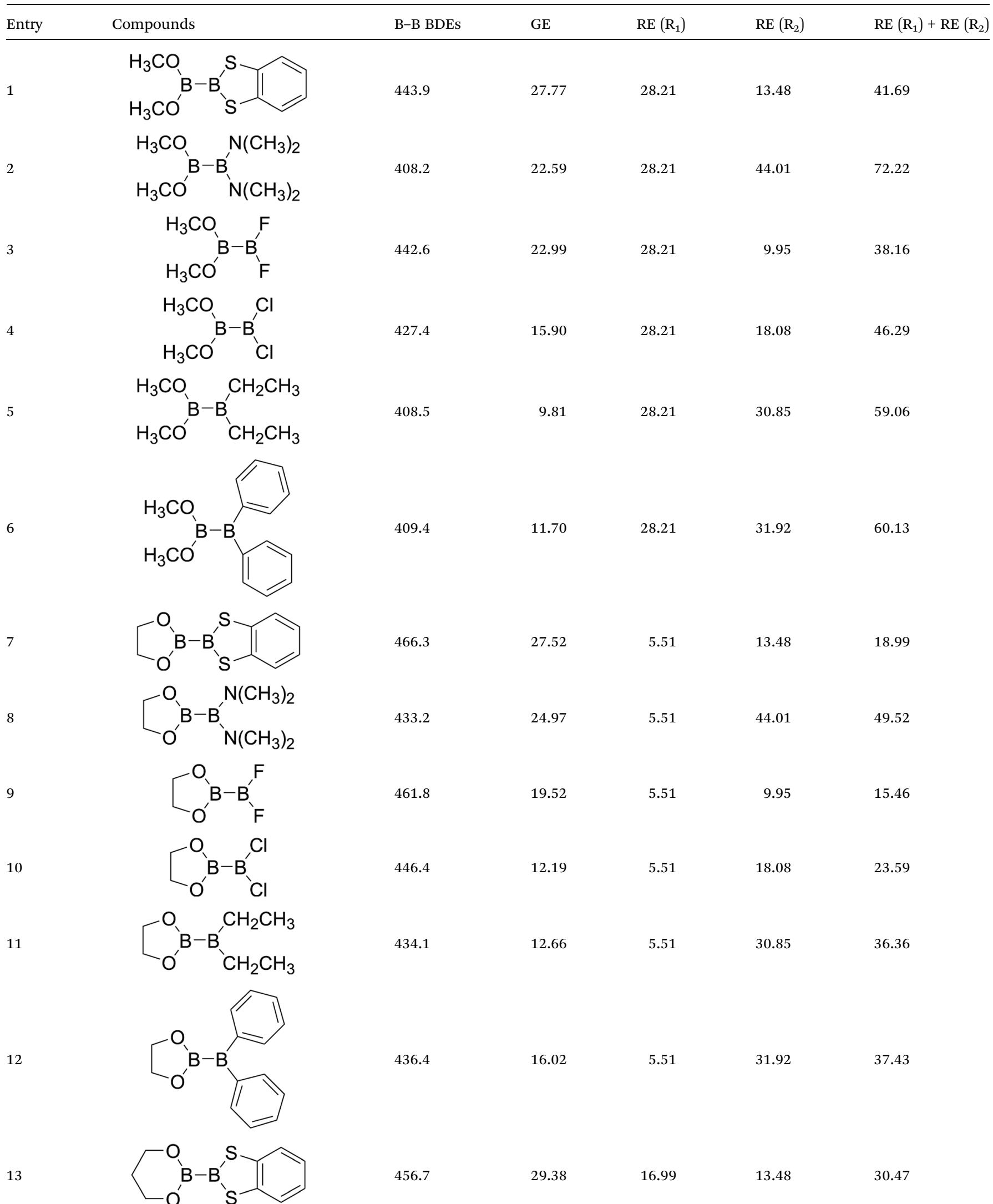


Table 4 (Contd.)

\begin{tabular}{|c|c|c|c|c|c|c|}
\hline Entry & Compounds & B-B BDEs & GE & $\mathrm{RE}\left(\mathrm{R}_{1}\right)$ & $\mathrm{RE}\left(\mathrm{R}_{2}\right)$ & $\mathrm{RE}\left(\mathrm{R}_{1}\right)+\mathrm{RE}\left(\mathrm{R}_{2}\right)$ \\
\hline 14 & & 415.6 & 18.81 & 16.99 & 44.01 & 61.00 \\
\hline 15 & & 454.5 & 23.66 & 16.99 & 9.95 & 26.94 \\
\hline 16 & & 438.4 & 15.74 & 16.99 & 18.08 & 35.07 \\
\hline 17 & & 419.9 & 9.96 & 16.99 & 30.85 & 47.84 \\
\hline 18 & & 421.7 & 12.83 & 16.99 & 31.92 & 48.91 \\
\hline 19 & & 476.8 & 30.53 & -2.01 & 13.48 & 11.47 \\
\hline 20 & & 445.9 & 30.09 & -2.01 & 44.01 & 42.00 \\
\hline 21 & & 469.4 & 19.58 & -2.01 & 9.95 & 7.94 \\
\hline 22 & & 454.1 & 12.34 & -2.01 & 18.08 & 16.07 \\
\hline 23 & & 444.1 & 15.18 & -2.01 & 30.85 & 28.84 \\
\hline 24 & & 445.8 & 17.96 & -2.01 & 31.92 & 29.91 \\
\hline 25 & & 429.8 & 29.49 & 13.48 & 44.01 & 57.49 \\
\hline 26 & & 459.0 & 24.64 & 13.48 & 9.95 & 23.43 \\
\hline
\end{tabular}


Table 4 (Contd.)

\begin{tabular}{|c|c|c|c|c|c|c|}
\hline Entry & Compounds & B-B BDEs & GE & $\mathrm{RE}\left(\mathrm{R}_{1}\right)$ & $\mathrm{RE}\left(\mathrm{R}_{2}\right)$ & $\mathrm{RE}\left(\mathrm{R}_{1}\right)+\mathrm{RE}\left(\mathrm{R}_{2}\right)$ \\
\hline 27 & & 443.5 & 17.31 & 13.48 & 18.08 & 31.56 \\
\hline 28 & & 431.3 & 17.83 & 13.48 & 30.85 & 44.33 \\
\hline 29 & & 430.9 & 18.48 & 13.48 & 31.92 & 45.40 \\
\hline 30 & & 433.0 & 29.19 & 44.01 & 9.95 & 53.96 \\
\hline 31 & (I) & 418.0 & 22.34 & 44.01 & 18.08 & 62.09 \\
\hline 32 & $\left(\mathrm{H}_{3} \mathrm{C}\right.$ & 386.9 & 3.97 & 44.01 & 30.85 & 74.86 \\
\hline 33 & & 389.5 & 7.65 & 44.01 & 31.92 & 75.93 \\
\hline 34 & & 433.6 & 3.84 & 9.95 & 18.08 & 28.03 \\
\hline 35 & & 432.8 & 15.82 & 9.95 & 30.85 & 40.80 \\
\hline 36 & & 432.8 & 16.90 & 9.95 & 31.92 & 41.87 \\
\hline 37 & & 423.4 & 14.58 & 18.08 & 30.85 & 48.93 \\
\hline 38 & & 420.9 & 13.09 & 18.08 & 31.92 & 50.00 \\
\hline
\end{tabular}


stability of molecule is strongly weakened while the stability of radical is greatly enhanced. On the contrary, for the $\left[2,2^{\prime}\right]$ bi [benzo[1,3,2]dioxaborolyl] (Entry 5) with the largest B-B BDE of $488.3 \mathrm{~kJ} \mathrm{~mol}^{-1}$, the GE value is a larger positive value (26.44 $\mathrm{kJ} \mathrm{mol}^{-1}$ ) while the RE value is a smaller absolute negative value $\left(-2.01 \mathrm{~kJ} \mathrm{~mol}^{-1}\right)$, and the opposite effect of GE and $\mathrm{RE}$ on the stability of the molecule and radical both lead to the remarkably increase of the $\mathrm{B}-\mathrm{B}$ BDE value. Moreover, for the $\mathrm{B}_{2} \mathrm{Cl}_{4}$ (Entry 12 ) with the $\mathrm{B}-\mathrm{B}$ BDE value of $423.6 \mathrm{~kJ} \mathrm{~mol}^{-1}$, the $\mathrm{GE}$ and $\mathrm{RE}$ are both positive values of $2.00 \mathrm{~kJ} \mathrm{~mol}^{-1}$ and $18.08 \mathrm{~kJ} \mathrm{~mol}^{-1}$, separately. It is obvious that the larger positive RE value has a stronger effect on $\mathrm{B}-\mathrm{B}$ $\mathrm{BDE}$ than the smaller positive GE value, which lead to the relatively smaller $\mathrm{B}-\mathrm{B} \mathrm{BDE}$ value. Besides, the linear relationships between GE values and RE values with B-B BDEs were obtained, which are depicted in Fig. 7(a) and (b). It can be seen that the correlation coefficient $R$ and slope between GE values with B-B BDEs are 0.759 and 1.64, while the correlation coefficient $R$ and slope between RE values with B-B BDEs are 0.892 and -2.61 , respectively. The larger absolute slope of RE values with B-B BDEs demonstrates that the RE has a stronger effect on B-B BDEs than GE for the 12 diboron(4) compounds.

The natural charges of atoms in molecules and radicals after B-B cleavage of representative diboron(4) compounds by the natural bond orbital (NBO) ${ }^{111}$ analysis at the SOGGA11$\mathrm{X} / 6-311++\mathrm{G}(2 \mathrm{df}, 2 \mathrm{p})$ level are shown in Fig. 8 and 9. Firstly, for the $\left[2,2^{\prime}\right]$ bi[benzo[1,3,2]dioxaborolyl] (Entry 5) and $\left[2,2^{\prime}\right]$ bi [benzo[1,3,2]dithiaborolyl] (Entry 6) compounds, the NBO analysis of molecules (in Fig. 8) gives the large positive natural charges $(0.824)$ for the two $\mathrm{B}$ atoms in $\left[2,2^{\prime}\right]$ bi [benzo $[1,3,2]$ dioxaborolyl], while the small absolute negative natural charges $(-0.092)$ on the two B atoms are found in $\left[2,2^{\prime}\right]$ bi[benzo[1,3,2]dithiaborolyl]. Meanwhile, the four $\mathrm{O}$ atoms in $\left[2,2^{\prime}\right]$ bi[benzo[1,3,2]dioxaborolyl] carry the large absolute negative charges $(-0.669)$ while the four $\mathrm{S}$ atoms in $\left[2,2^{\prime}\right]$ bi[benzo[1,3,2]dithiaborolyl] carry the small positive charges (0.215). The large difference of natural charge distributions may be related to the different optimized conformations of the two diboron(4) compounds which are shown in Fig. 6. And the natural charge distributions of their corresponding radicals (in Fig. 9) show that the B atom carry the large positive charge $(0.954)$ and the $\mathrm{O}$ atoms carry the large absolute negative charges $(-0.736)$ in benzo[1,3,2] dioxaborole, while the $\mathrm{B}$ and $\mathrm{S}$ atoms all carry the small positive charges $(0.117,0.109)$ in benzo[1,3,2]dithiaborole, which may be consistent with the large RE difference of the two compounds. Secondly, it is found that in the molecules of $\mathrm{B}_{2}\left(\mathrm{~N}\left(\mathrm{CH}_{3}\right)_{2}\right)_{4}$ and $\mathrm{B}_{2}\left(\mathrm{C}_{2} \mathrm{H}_{5}\right)_{4}$ as well as in the corresponding radicals, the natural charges of $\mathrm{B}$ atoms are both relatively smaller than those in $\mathrm{B}_{2}(\mathrm{OR})_{4}$ compound $\left[2,2^{\prime}\right]$ bi [benzo[1,3,2] dioxaborolyl]. In the compound of $\mathrm{B}_{2} \mathrm{~F}_{4}$ with plane conformation, the two $\mathrm{B}$ atoms carry the large positive natural charges (0.983) and the four $\mathrm{F}$ atoms carry the large absolute negative charges $(-0.491)$, in contrast, the B atoms carry small positive natural charges $(0.259)$ and the four $\mathrm{Cl}$ atoms carry the small absolute negative charges $(-0.130)$ in the compound of $\mathrm{B}_{2} \mathrm{Cl}_{4}$ with perpendicular conformation (in Fig. 8). Similarly, the significantly different charge distributions of $-\mathrm{BF}_{2}$ and $-\mathrm{BCl}_{2}$ are found.

In addition, the energies of frontier orbitals of the singly occupied molecular orbital (SOMO) of radicals after B-B cleavage were calculated, which are shown in Table 3. It can be seen that for the five $\mathrm{B}_{2}(\mathrm{OR})_{4}$ compounds, the SOMO energies are $-5.3 \mathrm{eV},-6.2 \mathrm{eV},-6.8 \mathrm{eV},-5.4 \mathrm{eV}$ and $-6.9 \mathrm{eV}$, respectively. The results indicated that the change of $\mathrm{B}-\mathrm{B}$ $\mathrm{BDE}$ values generally presents a trend, that is, the BDE value is higher, the absolute energy of the SOMO is larger, which
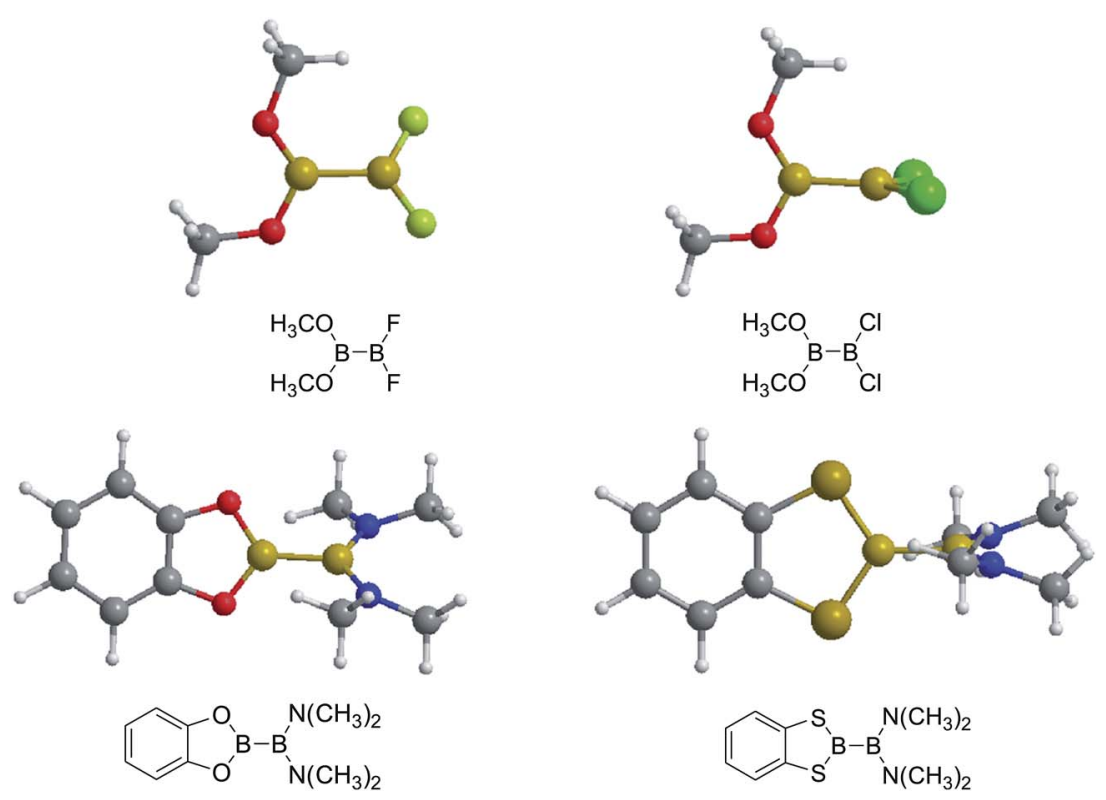

Fig. 10 The molecular optimized conformations at the B3LYP/6-31+G(d) level of four diboron(4) compounds in reaction (4). 


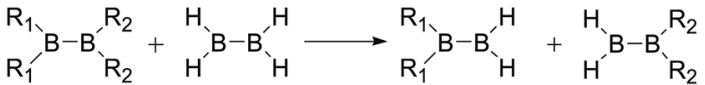

Scheme 2 GE of these diboron(4) compounds in reaction (4).

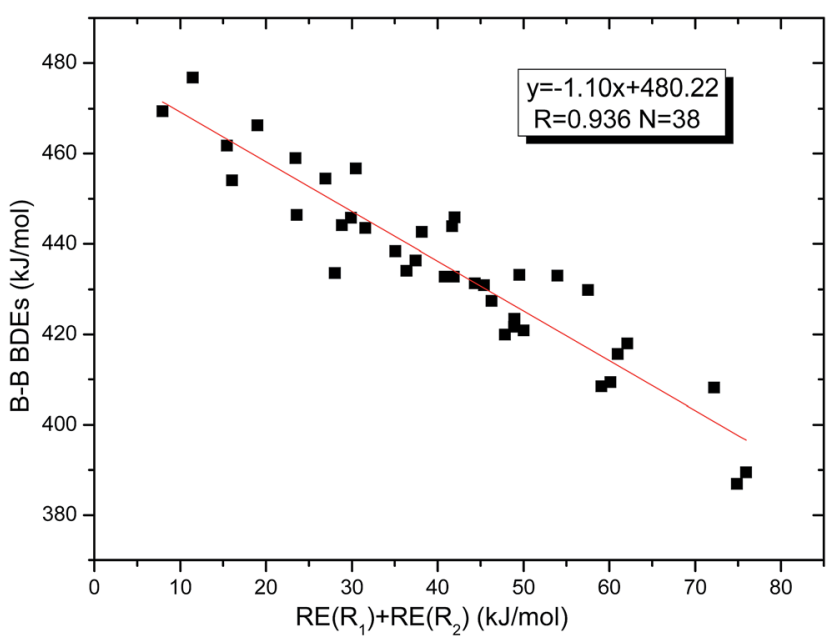

Fig. 11 Correlation between $R E\left(R_{1}\right)+R E\left(R_{2}\right)$ values with $B-B$ BDEs.

shows that the absolute energies of the SOMO are larger, the corresponding radicals are more instable. For the $\mathrm{B}_{2}(\mathrm{SR})_{4}$ compound of $\left[2,2^{\prime}\right]$ bi [benzo[1,3,2]dithiaborolyl] (Entry 6), the absolute energy of the SOMO is $0.4 \mathrm{eV}$ lower than $\left[2,2^{\prime}\right] \mathrm{bi}$ [benzo[1,3,2]dioxaborolyl] (Entry 5). For the $\mathrm{B}_{2}\left(\mathrm{NR}_{2}\right)_{4}$ and $\mathrm{B}_{2}(\mathrm{alkyl})_{4}$ compounds (Entries 7-10), the absolute energies of the SOMO were generally lower than other diboron(4) compounds. In addition, for the $\mathrm{B}_{2} \mathrm{X}_{4}$ compounds (Entries 11 and 12), absolute energies of the SOMO of $\mathrm{B}_{2} \mathrm{~F}_{4}$ is $0.8 \mathrm{eV}$ higher than $\mathrm{B}_{2} \mathrm{Cl}_{4}$. Apparently, we can come to the conclusion that the $\mathrm{B}-\mathrm{B}$ BDE change patterns of different $\mathrm{R}_{1}$ groups are in accordance with the absolute energies of the SOMO of the diboron(4) compounds.

Secondly, for the diboron(4) compounds that were shown in reaction (4), the B-B BDEs were calculated and the results were listed in the Table 4 . From the Table 4 , it can be seen that the largest B-B BDEs are found when $\mathrm{R}_{1}$ and $\mathrm{R}_{2}$ are both -OR or -SR groups and the smallest B-B BDEs are found when $R_{1}$ and $R_{2}$ are both $-N_{2}$ or -alkyl groups. For example, for all of the diboron(4) compounds, the largest and smallest B-B BDEs are found in $\mathrm{R}_{1}=$ benzo[1,3,2]dioxaborole, $\mathrm{R}_{2}=$ benzo[1,3,2]dithiaborole (Entry 19) and $\mathrm{R}_{1}=-\mathrm{N}\left(\mathrm{CH}_{3}\right)_{2}, \mathrm{R}_{2}=$

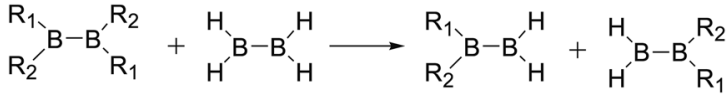

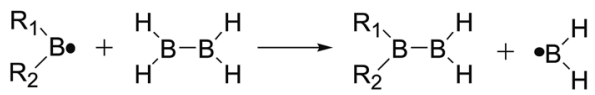

Scheme 3 GE (a) and RE (b) of these diboron(4) compounds in reaction (5).

$-\mathrm{CH}_{2} \mathrm{CH}_{3}$ (Entry 32), and the BDE values are $476.8 \mathrm{~kJ} \mathrm{~mol}^{-1}$ and $386.9 \mathrm{~kJ} \mathrm{~mol}^{-1}$, respectively. When only one of the substituents, i.e. $\mathrm{R}_{1}$ (or $\mathrm{R}_{2}$ ) is -OR or-SR groups, the BDEs are relatively larger while when only one of the substituents, i.e. $\mathrm{R}_{1}$ (or $\mathrm{R}_{2}$ ) is $-\mathrm{NR}_{2}$ or -alkyl groups, the $\mathrm{B}-\mathrm{B}$ BDEs are relatively smaller. For example, for $\mathrm{R}_{1}=[1,3,2]$ dioxaborolane, $\mathrm{R}_{2}=-\mathrm{Cl}$ (Entry 10), the B-B BDE is $446.4 \mathrm{~kJ} \mathrm{~mol}^{-1}$ and for $\mathrm{R}_{1}=$ $-\mathrm{N}\left(\mathrm{CH}_{3}\right)_{2}, \mathrm{R}_{2}=-\mathrm{Cl}$ (Entry 31), the B-B BDE is $418.0 \mathrm{~kJ} \mathrm{~mol}^{-1}$. Comparing the $\mathrm{B}-\mathrm{B}$ BDEs of $\mathrm{R}_{1}$ (or $\mathrm{R}_{2}$ ) $=-\mathrm{F}$ with $-\mathrm{Cl}$, it is found that the B-B BDEs of $-\mathrm{F}$ are about $15 \mathrm{~kJ} \mathrm{~mol}^{-1}$ larger than $-\mathrm{Cl}$. For example, for $\mathrm{R}_{1}=-\mathrm{OCH}_{3}, \mathrm{R}_{2}=-\mathrm{F}$ (Entry 3 ), the $\mathrm{B}-\mathrm{B} \mathrm{BDE}$ is $442.6 \mathrm{~kJ} \mathrm{~mol}^{-1}$ (with plane conformation in Fig. 10) while for $\mathrm{R}_{1}=-\mathrm{OCH}_{3}, \mathrm{R}_{2}=-\mathrm{Cl}$ (Entry 4), the B-B BDE is $427.4 \mathrm{~kJ} \mathrm{~mol}^{-1}$ (with perpendicular conformation in Fig. 10), and the difference between them is $15.2 \mathrm{~kJ} \mathrm{~mol}^{-1}$. Besides, comparing $\mathrm{R}_{1}=$ benzo[1,3,2]dioxaborole with $\mathrm{R}_{1}=$ benzo[1,3,2]dithiaborole (Entries 20-29), it can be seen that the B-B BDEs of $\mathrm{R}_{1}=$ benzo[1,3,2]dithiaborole are smaller, for example, for $\mathrm{R}_{1}=$ benzo[1,3,2]dioxaborole, $\mathrm{R}_{2}=$ $-\mathrm{N}\left(\mathrm{CH}_{3}\right)_{2}$, the B-B BDE value is $445.9 \mathrm{~kJ} \mathrm{~mol}^{-1}$ (with distorted conformation in Fig. 10) while for $\mathrm{R}_{1}=$ benzo[1,3,2]dithiaborole, $\mathrm{R}_{2}=-\mathrm{N}\left(\mathrm{CH}_{3}\right)_{2}$, the B-B BDE value is $429.8 \mathrm{~kJ} \mathrm{~mol}^{-1}$ (with perpendicular conformation in Fig. 10), and the difference between them is $16.1 \mathrm{~kJ} \mathrm{~mol}^{-1}$.

Similar with reaction (3), the GE values of these diboron(4) compounds in reaction (4) defined by the enthalpy change of the reaction in Scheme 2 are listed in the Table 4. Meanwhile, the RE values of corresponding radicals which were calculated in reaction (3) are also listed in the Table 4. In order to investigate the total effects of the two substituents $R_{1}$ and $R_{2}$ on B-B BDEs, the overall RE values, i.e. the sum of the $\mathrm{RE}\left(\mathrm{R}_{1}\right)$ and $R E\left(R_{2}\right)$ are listed in the Table 4 . It can be seen that all of the $\mathrm{GE}$ values and the overall $\mathrm{RE}$ values are positive. In addition, by observing the $38 \mathrm{~B}-\mathrm{B}$ BDE values as well as the corresponding GE and overall $\mathrm{RE}$ values of diboron(4) compounds with different $R_{1}$ and $R_{2}$ groups, it is found that

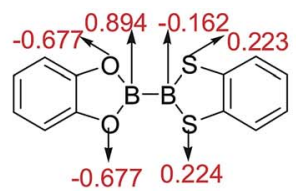

B-B BDEs (kJ/mol)

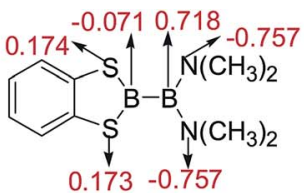

429.8

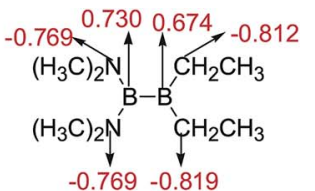

386.9

Fig. 12 Natural charges of atoms in molecules of representative diboron(4) compounds. 
Table 5 The B-B BDEs, orbital energies as well as the GE and RE values of diboron(4) compounds in reaction (5)

\begin{tabular}{|c|c|c|c|c|}
\hline Entry & Compounds & BDEs $\left(\mathrm{kJ} \mathrm{mol}^{-1}\right)$ & $\mathrm{GE}\left(\mathrm{kJ} \mathrm{mol}^{-1}\right)$ & $\mathrm{RE}\left(\mathrm{kJ} \mathrm{mol}^{-1}\right)$ \\
\hline 1 & $\begin{array}{r}F_{\backslash} \\
\left(\mathrm{H}_{3} \mathrm{C}\right)_{2} \mathrm{~N}^{\prime}\end{array}$ & 437.9 & 29.41 & 24.66 \\
\hline 2 & $\left(\mathrm{H}_{3} \mathrm{C}\right)_{2} \mathrm{~N}^{\prime}$ & 426.5 & 15.79 & 23.54 \\
\hline 3 & $\left(\mathrm{H}_{3} \mathrm{C}\right)_{3} \mathrm{C}$ & 398.3 & 10.50 & 34.97 \\
\hline 4 & $\begin{array}{r}\mathrm{Cl} \\
\left(\mathrm{H}_{3} \mathrm{C}\right)_{3} \mathrm{C}^{\prime}\end{array}$ & 411.1 & 4.36 & 25.52 \\
\hline 5 & $\begin{array}{r}\mathrm{H}_{3} \mathrm{CO} \\
\left(\mathrm{H}_{3} \mathrm{C}\right)_{2} \mathrm{~N}^{\prime}\end{array}$ & 410.3 & 23.84 & 35.68 \\
\hline 6 & $\begin{array}{l}\left(\mathrm{H}_{3} \mathrm{C}\right)_{3} \mathrm{C} \text { 、 } \\
\left(\mathrm{H}_{3} \mathrm{C}\right)_{2} \mathrm{~N}^{\prime}\end{array}$ & 375.3 & -7.19 & 37.65 \\
\hline 7 & $\begin{array}{r}\mathrm{H}_{3} \mathrm{CO} \\
\left(\mathrm{H}_{3} \mathrm{C}\right)_{3} \mathrm{C}^{\prime}\end{array}$ & 383.2 & 5.41 & 39.97 \\
\hline 8 & $\mathrm{H}$ & 448.5 & 20.66 & 14.99 \\
\hline 9 & $\begin{array}{r}\mathrm{H}_{3} \mathrm{CO} \\
\mathrm{Cl}^{\prime}\end{array}$ & 431.9 & 12.54 & 19.19 \\
\hline 10 & $\mathrm{Cl}^{\prime \prime}$ & 428.9 & 3.49 & 16.20 \\
\hline
\end{tabular}

the B-B BDE values are determined by the co-effects of GE and overall RE. For example, for the diboron(4) compound in which $\mathrm{R}_{1}=$ benzo[1,3,2]dioxaborole and $\mathrm{R}_{2}=$ benzo[1,3,2] dithiaborole, the $\mathrm{B}-\mathrm{B}$ BDE value is the largest of $476.8 \mathrm{~kJ} \mathrm{~mol}^{-1}$, and the $\mathrm{GE}$ is a larger positive value (30.53 $\mathrm{kJ} \mathrm{mol}^{-1}$ ) while the overall $\mathrm{RE}$ is a smaller positive value $\left(11.47 \mathrm{~kJ} \mathrm{~mol}^{-1}\right)$, it is clear that the $\mathrm{GE}$ has a stronger effect on B-B BDE than the overall RE. For the diboron(4) compound in which $\mathrm{R}_{1}=-\mathrm{N}\left(\mathrm{CH}_{3}\right)_{2}$ and $\mathrm{R}_{2}=-\mathrm{CH}_{2} \mathrm{CH}_{3}$, the $\mathrm{B}-\mathrm{B} \mathrm{BDE}$ value is the smallest of $386.9 \mathrm{~kJ} \mathrm{~mol}^{-1}$, and the GE is a smaller positive value $\left(3.97 \mathrm{~kJ} \mathrm{~mol}^{-1}\right)$ while the overall $\mathrm{RE}$ is a larger positive value $\left(74.86 \mathrm{~kJ} \mathrm{~mol}^{-1}\right)$, which shows that the overall RE plays a more important role on B-B BDE than GE. Besides, the linear relationship between the overall $\mathrm{RE}$ values with B-B BDEs was obtained, which is depicted in Fig. 11. It can be seen that the correlation coefficient $R$ and slope are 0.936 and -1.10 , respectively. The excellent correlation coefficient demonstrates that the B-B BDE change patterns in reaction (4) are in good agreement with the values of the sum of the $\mathrm{RE}\left(\mathrm{R}_{1}\right)$ and $\mathrm{RE}\left(\mathrm{R}_{2}\right)$.
The natural charges of atoms in molecules of three representative diboron(4) compounds in which there is a large B-B BDE difference by the NBO analysis are shown in Fig. 12. It is found that the natural charges of $B$ atoms which are connected to the $-\mathrm{OR}(-\mathrm{OR}=$ benzo[ $[1,3,2]$ dioxaborole $)$, $-\mathrm{N}\left(\mathrm{CH}_{3}\right)_{2}$ and $-\mathrm{CH}_{2} \mathrm{CH}_{3}$ groups are larger positive, while the natural charges of the $\mathrm{B}$ atoms which are connected to the -SR group $(-\mathrm{SR}=$ benzo[1,3,2]dithiaborole) are smaller absolute negative. In addition, in the $-\mathrm{OR}(-\mathrm{OR}=$ benzo $[1,3,2]$ dioxaborole), $-\mathrm{N}\left(\mathrm{CH}_{3}\right)_{2}$ and $-\mathrm{CH}_{2} \mathrm{CH}_{3}$ groups, the natural charges of $\mathrm{O}, \mathrm{N}$ and $\mathrm{C}$ atoms are larger absolute negative, while in the $-\mathrm{SR}$ group $(-\mathrm{SR}=$ benzo[1,3,2]dithiaborole), the natural charges of $\mathrm{S}$ atoms are smaller positive. Apparently, the different substituents can lead to large differences in the natural charge distributions of atoms.

Thirdly, the B-B BDEs of diboron(4) compounds that were shown in reaction (5) were calculated and the values are listed in the Table 5. From the Table 5, it can be found that the only difference between the diboron(4) compounds in reaction (5) and reaction (4) is the $R_{1}$ and $R_{2}$ substituent 


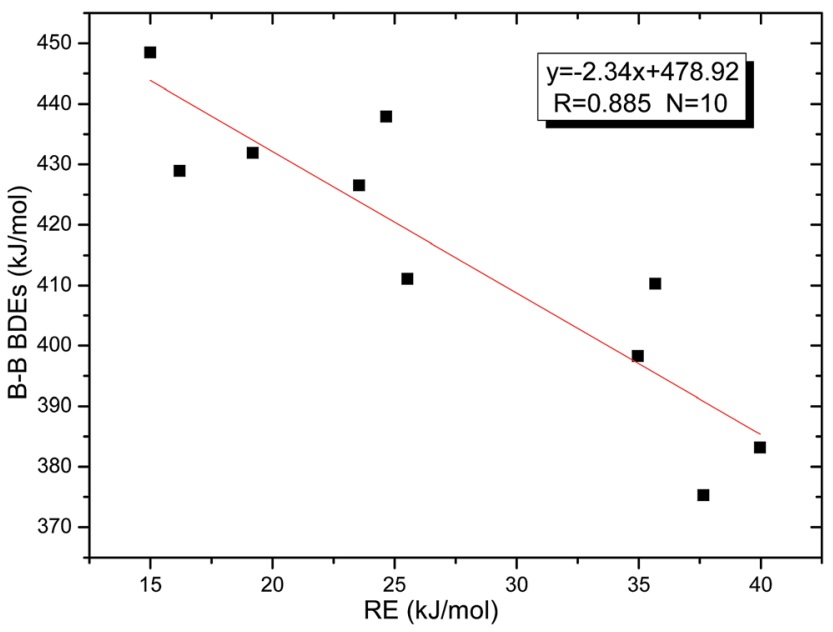

Fig. 13 Correlation between RE values with B-B BDEs.

positions, that is, the symmetry of diboron(4) compounds is different. Comparing the B-B BDEs of the two types of the compounds in Tables 4 and 5 , the small differences between them can be found, which indicates that the positions of the substituent groups $R_{1}$ and $R_{2}$ have little influence on the B-B BDEs. For example, when $\mathrm{R}_{1}=-\mathrm{F}$ and $\mathrm{R}_{2}=-\mathrm{N}\left(\mathrm{CH}_{3}\right)_{2}$ (Entry 1 in Table 5), the B-B BDE is $437.9 \mathrm{~kJ} \mathrm{~mol}^{-1}$, while for the same substituent groups in Table 4 (Entry 30), the B-B BDE is $433.0 \mathrm{~kJ} \mathrm{~mol}^{-1}$, and there is only $4.9 \mathrm{~kJ} \mathrm{~mol}^{-1}$ difference between them. Herein, similar with reaction (3), the GE and $\mathrm{RE}$ of these diboron(4) compounds are defined by the enthalpy changes of the reactions (a) and (b) in Scheme 3, and the values are also listed in the Table 5. Comparing the GE values of the diboron(4) compounds in Tables 5 and 4, it is found that there is little difference between the corresponding GE values of the two types of the compounds, which indicates that the different positions of the substituent groups $R_{1}$ and $R_{2}$ have little effect on the stability of the molecules. In addition, the linear relationship between the RE values with B-B BDEs was obtained, which is depicted in Fig. 13. It can be seen that the correlation coefficient $R$ and slope are 0.885 and -2.34 , respectively, which is better than the correlation between the GE values with B-B BDEs $(y=$ $1.48 x+397.61, R=0.624)$. The larger absolute slope of $\mathrm{RE}$ values with B-B BDEs $(-2.34)$ shows that the RE plays a stronger role on the B-B BDEs than GE for all of the 10 diboron(4) compounds.

\subsection{The Pt-B and $\mathrm{Cu}-\mathrm{B}$ BDE predictions after B-B cleavages}

In the quantities of experimental studies on the synthetic reactions involving $\mathrm{B}-\mathrm{B}$ cleavage, the transitional-metal catalysts such as $\mathrm{Pt}, \mathrm{Pd}, \mathrm{Ni}, \mathrm{Cu}$, etc. were universally used. There remain some interesting problems, for example, how the different transition metals specifically affect the B-B cleavage in the reaction process? What are the conformations of the complexes formed after the B-B cleavage? How do the different substituents that appeared in the diboron(4) compounds affect the stability of these complexes? Therefore, in order to better understand the catalytic process involving B-B cleavage by the transitional-metal catalysts, in our present study, the $\mathrm{Pt}$ and $\mathrm{Cu}$ catalysts were selected as the representatives.

The platinum(0) complexes are generally considered to be very effective and common catalysts for the diboration reaction process, ${ }^{\mathbf{1 1 4 - 1 1 7}}$ and the catalytic cycling process mainly includes the three steps: oxidative addition (Scheme 4(a)), coordinate on and insertion one of the $\mathrm{Pt}-\mathrm{B}$ bonds, reductive elimination. ${ }^{\mathbf{1 4 1 1 8}}$ The copper(I) complexes are used as a new and useful catalytic tool for the diboration process, ${ }^{\mathbf{1 1 6 , 1 1 9 - 1 2 1}}$ and there are a series of $\sigma$-bond metathesis steps in this reaction process, in which the $\mathrm{Cu}-\mathrm{B}$ bond is formed in the initial metathesis step (Scheme 4(b)) and the two boryl groups are eventually transferred to the substrate. ${ }^{1}$ Apparently, the $\mathrm{Pt}-\mathrm{B}$ and $\mathrm{Cu}-\mathrm{B}$ bonds play an important role in the whole reaction process. How about the strength of the newly formed $\mathrm{Pt}-\mathrm{B}$ and $\mathrm{Cu}-\mathrm{B}$ bonds after the $\mathrm{B}-\mathrm{B}$ cleavage? Therefore, the $\mathrm{Pt}-\mathrm{B}$ and $\mathrm{Cu}-\mathrm{B}$ BDEs were calculated by using the SOGGA11-X method and the values are listed in the Table 6. In addition, the ligand $\mathrm{L}$ is selected as the $\mathrm{P}\left(\mathrm{CH}_{3}\right)_{3}$ for the copper(I) complexes.

By comparing the $\mathrm{Pt}-\mathrm{B}$ and $\mathrm{Cu}-\mathrm{B}$ BDEs of transition metal boryl complexes with the corresponding B-B BDEs of diboron(4) compounds (in the Table 3), it is found that the $\mathrm{Pt}-\mathrm{B}$ and $\mathrm{Cu}-\mathrm{B}$ BDEs are greatly reduced. The $\triangle \mathrm{BDE}$ values between Pt-B and B-B BDEs as well as $\mathrm{Cu}-\mathrm{B}$ and $\mathrm{B}-\mathrm{B}$ BDEs are also listed in the Table 6. For the Pt-B BDEs, it is found that the BDE values are largely reduced (over $100 \mathrm{~kJ} \mathrm{~mol}^{-1}$ ) when $\mathrm{R}_{1}$ are $-\mathrm{OR},-\mathrm{SR},-\mathrm{NR}_{2}$ and -alkyl groups, especially when $\mathrm{R}_{1}$ is $-\mathrm{C}\left(\mathrm{CH}_{3}\right)_{3}$, the Pt-B BDE value is reduced as high as $190.9 \mathrm{~kJ} \mathrm{~mol}^{-1}$. However, when $\mathrm{R}_{1}$ are $-\mathrm{F}$ and $-\mathrm{Cl}$ groups, the Pt-B BDE values are reduced by $86.8 \mathrm{~kJ} \mathrm{~mol}^{-1}$ and $86.9 \mathrm{~kJ} \mathrm{~mol}^{-1}$, separately. For the Cu-B BDEs, it can be seen that the $\mathrm{Cu}-\mathrm{B}$ BDE values are decreased by over $100 \mathrm{~kJ} \mathrm{~mol}^{-1}$

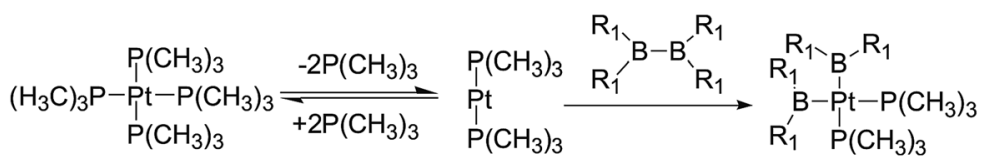

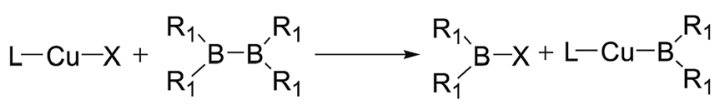

Scheme 4 The formation of the Pt-B and $\mathrm{Cu}-\mathrm{B}$ bonds in the catalytic process. 


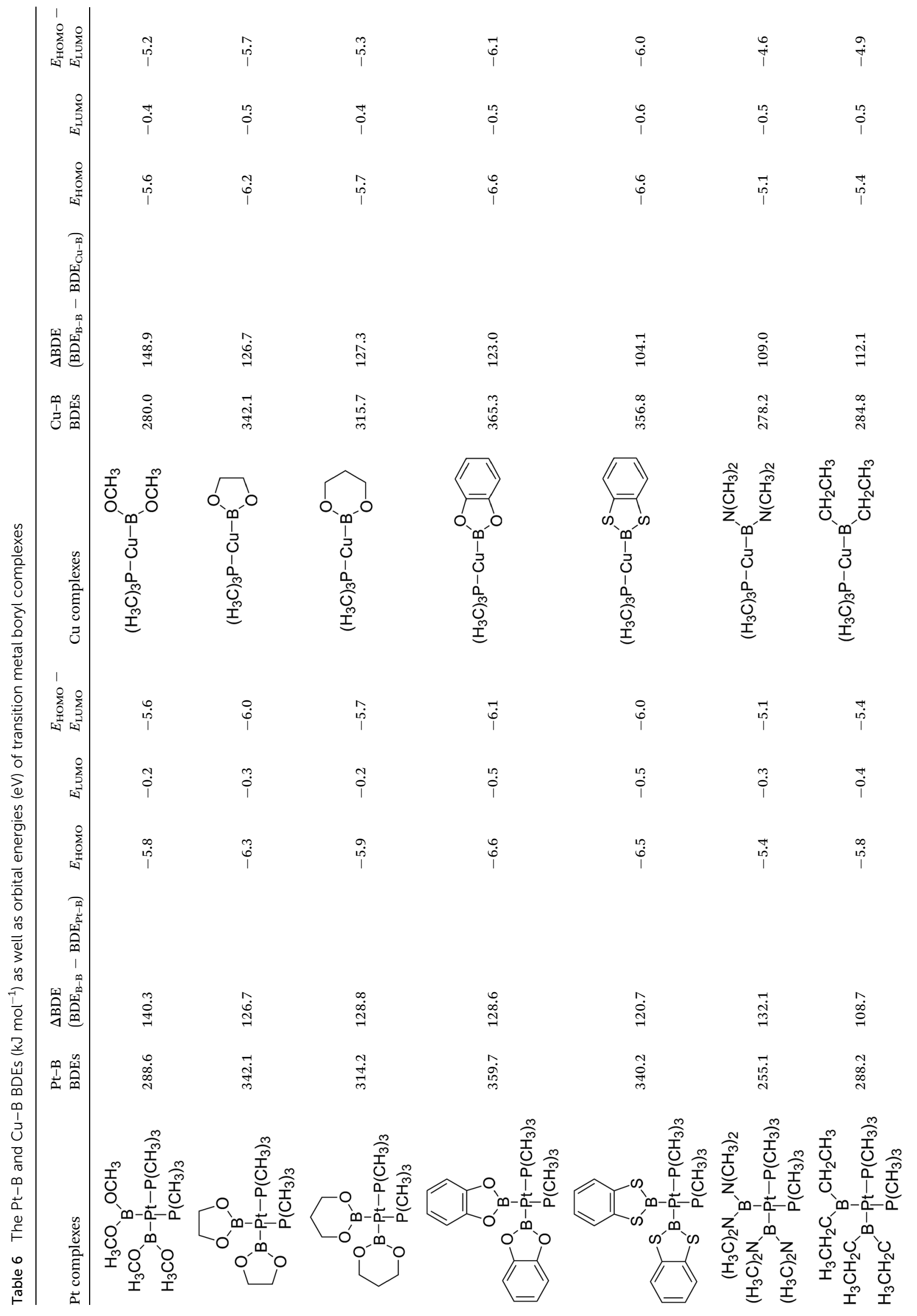


$\stackrel{9}{+}$
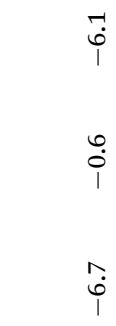

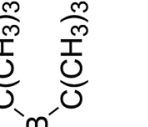

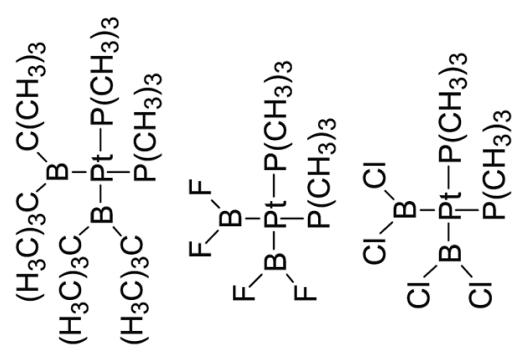

except for the $\mathrm{R}_{1}$ are $-\mathrm{C}\left(\mathrm{CH}_{3}\right)_{3}, \quad-\mathrm{F}$ and $-\mathrm{Cl}$ groups $\left(73.2 \mathrm{~kJ} \mathrm{~mol}^{-1}, 89.5 \mathrm{~kJ} \mathrm{~mol}^{-1}\right.$ and $\left.82.1 \mathrm{~kJ} \mathrm{~mol}^{-1}\right)$. The results indicate that the participation of transition metals such as $\mathrm{Pt}$ and $\mathrm{Cu}$ makes the $\mathrm{B}-\mathrm{B}$ cleavages become much easier, so that the subsequent processes of the whole reaction can proceed smoothly and the desired products can be obtained. By comparison, when $\mathrm{R}_{1}$ is $-\mathrm{C}\left(\mathrm{CH}_{3}\right)_{3}$, the $\mathrm{Pt}-\mathrm{B}$ BDE is much lower than the $\mathrm{Cu}-\mathrm{B} \mathrm{BDE}$, which indicates that the $-\mathrm{C}\left(\mathrm{CH}_{3}\right)_{3}$ group is much more favorable to the $\mathrm{B}-\mathrm{B}$ cleavage under the condition of platinum than copper catalyst from the thermodynamic viewpoint. For the $\mathrm{Pt}-\mathrm{B}$ and $\mathrm{Cu}-\mathrm{B}$ BDEs with different substituents, it can be seen that the $-\mathrm{OCH}_{3},-\mathrm{NR}_{2}$ and -alkyl groups are disadvantageous for the complexes stability, that is, the $\mathrm{Pt}-\mathrm{B}$ and $\mathrm{Cu}-\mathrm{B}$ cleavages are more favorable and the boryl groups can be better transferred to the substrates.

The energies of frontier orbitals including the highest occupied molecular orbital (HOMO) and the lowest unoccupied molecular orbital (LUMO) of molecules as well as the differences between HOMO and LUMO are also listed in Table 6. From the Table 6, it is found that the $\mathrm{Pt}-\mathrm{B}$ and $\mathrm{Cu}-\mathrm{B}$ $B D E$ values are larger (except for the Pt-B BDE of $R_{1}$ is $\left.-\mathrm{C}\left(\mathrm{CH}_{3}\right)_{3}\right)$, the absolute energy differences between HOMO and LUMO ( $E_{\text {номо }}-E_{\text {LUMO }}$ in Table 6) are larger too. The larger absolute energy differences indicate that the corresponding molecules are more difficult to be activated. In addition, the two good linear relationships between Pt-B (except for the Pt-B BDE of $\mathrm{R}_{1}$ is $-\mathrm{C}\left(\mathrm{CH}_{3}\right)_{3}$ ) and $\mathrm{Cu}-\mathrm{B}$ BDEs with their corresponding $E_{\text {номо }}-E_{\text {LUмо }}$ were obtained, which are depicted in Fig. 14(a) and (b). It can be seen that the slope between Pt-B BDEs with $E_{\mathrm{HOMO}}-E_{\mathrm{LUMO}}$ is -79.17 , while the slope between $\mathrm{Cu}-\mathrm{B}$ BDEs with $E_{\text {Hомо }}-E_{\mathrm{LUMO}}$ is -64.06 , which demonstrates that the orbital energy effect of platinum complexes is more pronounced than copper complexes.

The optimized conformations of platinum complexes with different $\mathrm{R}_{1}$ groups such as $[1,3,2]$ dioxaborinane, $-\mathrm{C}\left(\mathrm{CH}_{3}\right)_{3}$, $-\mathrm{F}$ and the corresponding $\mathrm{Pt}-\mathrm{B}$ bond lengths as well as the bond angles (B-Pt-B) are shown in Fig. 15. It can be found that the Pt-B bond lengths are all around $2.000 \AA$, and the three bond angles are $76.38^{\circ}, 94.75^{\circ}$ and $79.64^{\circ}$, respectively. Moreover, when $R_{1}$ are $[1,3,2]$ dioxaborinane and $-F$ groups, the Pt center exhibits planar conformation, while when $\mathrm{R}_{1}$ is $-\mathrm{C}\left(\mathrm{CH}_{3}\right)_{3}$, the Pt center is non-planar, which may lead to their Pt-B BDE difference. In addition, for all of the copper complexes with different $\mathrm{R}_{1}$ groups, the $\mathrm{Cu}$ centers exhibit linear conformations (not shown in Fig. 15).

\subsection{The B-B BDE predictions of several diboron(4) compounds}

In our calculations, the B-B BDE predictions of several diboron(4) compounds which were used by experimental chemists in the lab have also been conducted by using SOGGA11-X method, and the values are listed in the Table S2 in the ESI. $\dagger$ These theoretical values can provide experimental chemists with the constructive guidance for 


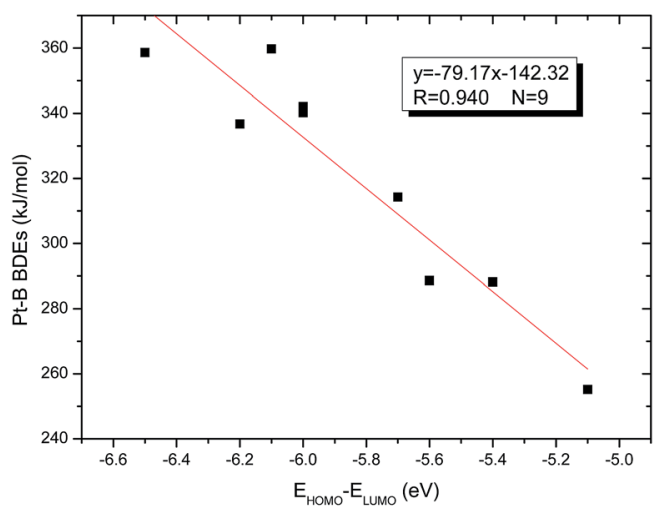

(a)

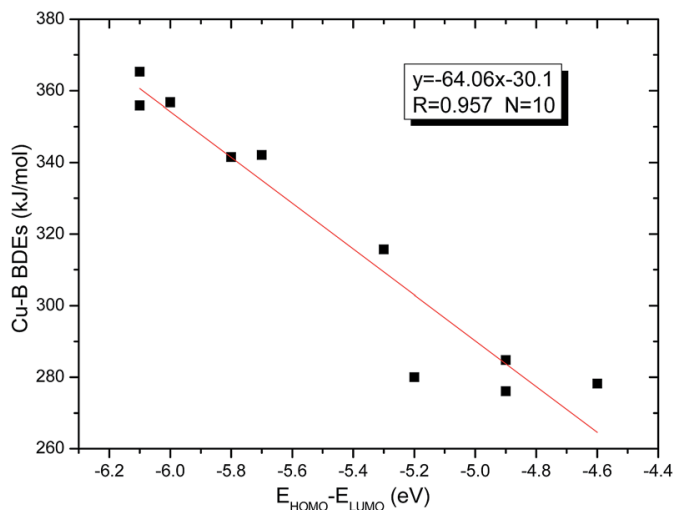

(b)

Fig. 14 (a) Correlation between Pt-B BDEs with $E_{\mathrm{HOMO}}-E_{\mathrm{LUMO}}$. (b) Correlation between $\mathrm{Cu}-\mathrm{B}$ BDEs with $E_{\mathrm{HOMO}}-E_{\mathrm{LUMO}}$.
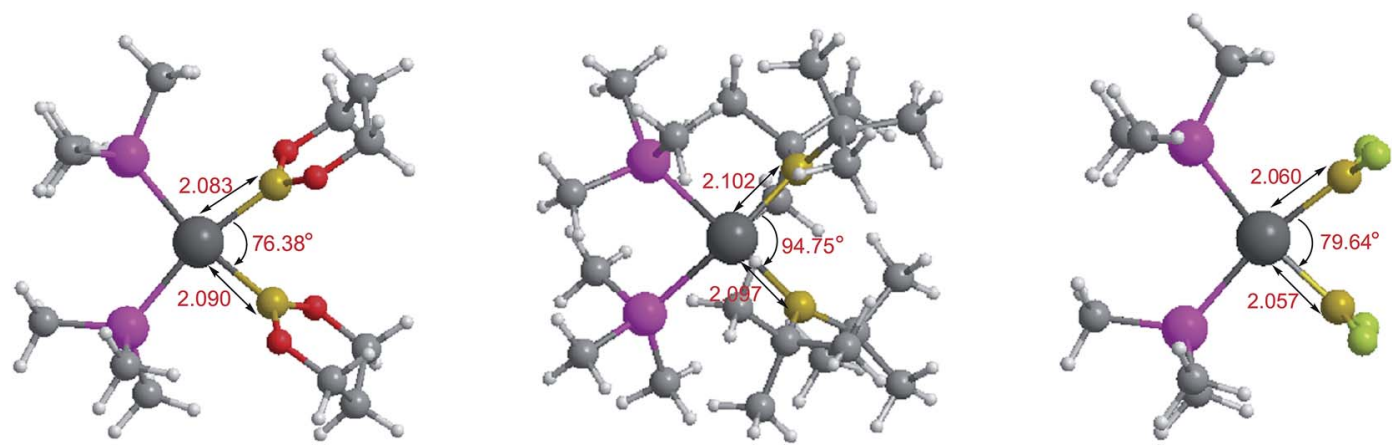

Fig. 15 The optimized conformations of platinum complexes with different $\mathrm{R}_{1}$ groups.

the design and development of the diboranes in the reactions.

\section{Conclusions}

The organic synthesis reactions of diboron(4) compounds in which B-B cleavages are involved can introduce a new set of boron-containing organic reagents that was proven to be very useful in many organic synthetic routes and be regarded as ideal candidates for green chemistry. Therefore, it is significant to understand one of the thermodynamic properties of the $\mathrm{B}-\mathrm{B}$ bond, the strength of the B-B bond, which can be measured by using the homolytic bond dissociation enthalpies (BDEs). In our present study, the 34 diboron(4) compounds in which no more than 6 non-hydrogen atoms are included were selected as the training set and the B-B BDEs were calculated by using the theoretical methods including composite high-level $a b$ initio methods such as G3, G3B3, G4, G4MP2, CBS-Q, CBS-QB3, ROCBS-QB3 and CBS-4M as well as 28 density functional theory (DFT) methods. The results show that it is reasonable and reliable to regard the $34 \mathrm{~B}-\mathrm{B} \mathrm{BDE}$ averages of the five highlevel methods including G3, G3B3, CBS-Q, CBS-QB3 and ROCBS-QB3 as the standard reference B-B BDEs, and the SOGGA11-X method is the most accurate method to predict the B-B BDE values with the smallest RMSE value of $4.4 \mathrm{~kJ} \mathrm{~mol}^{-1}$.
The linear correlation coefficient $(R)$ between the $34 \mathrm{~B}-\mathrm{B}$ BDEs calculated by SOGGA11-X method and the standard reference $\mathrm{B}-\mathrm{B} \mathrm{BDE}$ values is 0.955 . Therefore, the B-B BDEs of three types of diboron(4) compounds according to their different molecular symmetry were investigated in detail by using the SOGGA11-X method. The NBO analysis, the GE and RE as well as the frontier orbital energy analysis were performed to further disclose the essence of corresponding BDE change patterns. In order to better understand the catalytic process involving $\mathrm{B}-\mathrm{B}$ cleavages by the transitional-metal catalysts, the $\mathrm{Pt}-\mathrm{B}$ and $\mathrm{Cu}-\mathrm{B}$ BDE predictions after $\mathrm{B}-\mathrm{B}$ cleavages were also conducted at this level. In addition, the B-B BDE values of several diboron(4) compounds which were used by experimental chemists in the lab were also predicted by using the SOGGA11-X method. The major conclusions are summarized as follows:

(1) In the B-B BDE prediction of diboron(4) compounds in reaction (3), it is found that when $\mathrm{R}_{1}$ groups are $-\mathrm{OR},-\mathrm{SR},-\mathrm{F}$ and $-\mathrm{Cl}$, the $\mathrm{B}-\mathrm{B}$ BDEs are larger while when $\mathrm{R}_{1}$ groups are $-\mathrm{NR}_{2}$ and -alkyl, the B-B BDEs are smaller. The GE and RE values provide a way to better understand the different $R_{1}$ effects on $\mathrm{B}-\mathrm{B}$ BDEs. The linear relationships between $\mathrm{GE}$ values and $\mathrm{RE}$ values with $\mathrm{B}-\mathrm{B}$ BDEs were obtained, which indicates that the $\mathrm{RE}$ has a stronger effect on B-B BDEs than GE for the 12 diboron(4) compounds. In addition, the NBO analysis and energies of frontier orbitals further illustrated the B-B BDE 
change patterns. It can be seen that the absolute energies of the SOMO are larger, the $\mathrm{B}-\mathrm{B} \mathrm{BDE}$ values are larger.

(2) In the B-B BDE prediction of diboron(4) compounds in reaction (4), it is found that when $\mathrm{R}_{1}$ and $\mathrm{R}_{2}$ are both -OR or -SR groups, the $\mathrm{B}-\mathrm{B}$ BDEs are largest while when $\mathrm{R}_{1}$ and $\mathrm{R}_{2}$ are both $-\mathrm{NR}_{2}$ or -alkyl groups, the B-B BDEs are smallest. Moreover, for the compounds that only one of the substituents, i.e. $\mathrm{R}_{1}$ (or $\mathrm{R}_{2}$ ) is -OR or -SR groups, the BDEs are relatively larger while for the compounds that only one of the substituents, i.e. $\mathrm{R}_{1}$ (or $\mathrm{R}_{2}$ ) is $-\mathrm{NR}_{2}$ or -alkyl groups, the $\mathrm{B}-\mathrm{B}$ BDEs are relatively smaller. In addition, it is found that the $\mathrm{B}-\mathrm{B} \mathrm{BDE}$ values are determined by the co-effects of GE and overall RE. The excellent linear relationship between the overall RE values with B-B BDEs demonstrates that the $\mathrm{B}-\mathrm{B} \mathrm{BDE}$ change patterns are in good agreement with the values of the sum of the RE $\left(R_{1}\right)$ and $R E\left(R_{2}\right)$.

(3) Comparing the B-B BDEs of the two types of diboron(4) compounds in reaction (5) and reaction (4), the small difference between them indicates that the positions of the substituent groups $\mathrm{R}_{1}$ and $\mathrm{R}_{2}$ have little influence on the B-B BDEs. Similarly, there is also little difference between the GE values of the two types of compounds, which indicates that the different positions of the $R_{1}$ and $R_{2}$ have little effect on the stability of the molecules. In addition, the linear relationship between the $\mathrm{RE}$ values with B-B BDEs was obtained, which is better than the correlation between the GE values with B-B BDEs, and the larger absolute slope of RE values with B-B BDEs shows that the $\mathrm{RE}$ plays a stronger role on the B-B BDEs than GE for all of the 10 diboron(4) compounds.

(4) In the $\mathrm{Pt}-\mathrm{B}$ and $\mathrm{Cu}-\mathrm{B}$ BDE predictions of transition metal boryl complexes with different substituents after B-B cleavage, it is found that the participation of transition metals such as $\mathrm{Pt}$ and $\mathrm{Cu}$ can make the $\mathrm{B}-\mathrm{B}$ cleavages much easier. The $\mathrm{Pt}-\mathrm{B} \mathrm{BDE}$ is much lower than the $\mathrm{Cu}-\mathrm{B} \mathrm{BDE}$ when $\mathrm{R}_{1}$ is $-\mathrm{C}\left(\mathrm{CH}_{3}\right)_{3}$, which indicates that the $-\mathrm{C}\left(\mathrm{CH}_{3}\right)_{3}$ group is much more favorable to the $\mathrm{B}-\mathrm{B}$ cleavage under the condition of platinum than copper catalyst from the thermodynamic viewpoint. By observing the Pt-B and $\mathrm{Cu}-\mathrm{B}$ BDEs with different $\mathrm{R}_{1}$ groups, it is found that the $-\mathrm{OCH}_{3}$, $-\mathrm{NR}_{2}$ and -alkyl groups are unfavorable for the complexes stability. In addition, the frontier orbitals energy analysis further illustrates the $\mathrm{Pt}-\mathrm{B}$ and $\mathrm{Cu}-\mathrm{B}$ BDE change patterns, and the two good linear relationships between $\mathrm{Pt}-\mathrm{B}$ and $\mathrm{Cu}-\mathrm{B}$ BDEs with their corresponding $E_{\mathrm{HOMO}}-E_{\mathrm{LUMO}}$ were obtained, and the results demonstrate that the orbital energy effect of platinum complexes is more prominent than copper complexes. In the optimized conformations of platinum complexes, it is found that the Pt centers exhibit planar conformations except for $R_{1}=-\mathrm{C}\left(\mathrm{CH}_{3}\right)_{3}$ group, while the $\mathrm{Cu}$ centers are all linear for the copper complexes with different $\mathrm{R}_{1}$ groups.

\section{Conflicts of interest}

There are no conflicts to declare.

\section{Acknowledgements}

This project is sponsored by the Shanghai University of Engineering Science Innovation Funds for Graduate Students (No.
16KY0412, No. 17KY0409). We also thank the Shanghai Supercomputer Center for the computational resources.

\section{References}

1 E. C. Neeve, S. J. Geier, I. A. I. Mkhalid, S. A. Westcott and T. B. Marder, Chem. Rev., 2016, 116, 9091-9161.

2 A. Stock, A. Brandt and H. Fischer, Ber. Dtsch. Chem. Ges. B, 1925, 58, 643-657.

3 W. Yang, X. Gao and B. Wang, Med. Res. Rev., 2003, 23, 346368.

4 H. Zhao, L. Dang, T. B. Marder and Z. Lin, J. Am. Chem. Soc., 2008, 130, 5586-5594.

5 C. Solé and E. Fernández, Chem.-Asian J, 2009, 4, 17901793.

6 A. L. Moure, R. Gómez Arráyas and J. C. Carretero, Chem. Commun., 2011, 47, 6701-6703.

7 K. Knott, J. Fishovitz, S. B. Thorpe, I. Lee and W. L. Santos, Org. Biomol. Chem., 2010, 8, 3451-3456.

8 H. E. Sailes, J. P. Watts and A. Whiting, J. Chem. Soc., Perkin Trans. 1, 2000, 3362-3374.

9 I. A. I. Mkhalid, J. H. Barnard, T. B. Marder, J. M. Murphy and J. F. Hartwig, Chem. Rev., 2010, 110, 890-931.

10 D. Qiu, L. Jin, Z. Zheng, H. Meng, F. Mo, X. Wang, Y. Zhang and J. B. Wang, J. Org. Chem., 2013, 78, 1923-1933.

11 A. J. J. Lennox and G. C. Lloyd-Jones, Chem. Soc. Rev., 2014, 43, 412-443.

12 G. Urry, J. Kerrigan, T. D. Parsons and H. Schlesinger, J. Am. Chem. Soc., 1954, 76, 5299-5301.

13 R. W. Rudolph, J. Am. Chem. Soc., 1967, 89, 4216-4217.

14 H. Braunschweig, Angew. Chem., Int. Ed., 1998, 37, 17861801.

15 B. Wrackmeyer, Angew. Chem., Int. Ed., 1999, 38, 771-772.

16 A. Bonet, C. Pubill-Ulldemolins, C. Bo, H. Gulyás and E. Fernández, Angew. Chem., Int. Ed., 2011, 50, 7158-7161.

17 A. Bonet, C. Solé, H. Gulyás and E. Fernández, Org. Biomol. Chem., 2012, 10, 6621-6623.

18 C. Pubill-Ulldemolins, A. Bonet, C. Bo, H. Gulyás and E. Fernández, Chem.-Eur. J., 2012, 18, 1121-1126.

19 K. Kubota, H. Iwamoto, E. Yamamoto and H. Ito, Org. Lett., 2015, 17, 620-623.

20 D. D. Vachhani, H. H. Butani, N. Sharma, U. C. Bhoya, A. K. Shah and E. V. Van der Eycken, Chem. Commun., 2015, 51, 14862-14865.

21 C. T. Yang, Z. Q. Zhang, H. Tajuddin, C. C. Wu, J. Liang, J. H. Liu, Y. Fu, M. Czyzewska, P. G. Steel, T. B. Marder and L. Liu, Angew. Chem., Int. Ed., 2012, 51, 528-532.

22 M. Shimizu, T. Fujimoto, H. Minezaki, T. Hata and T. Hiyama, J. Am. Chem. Soc., 2001, 123, 6947-6948.

23 S. Crotti, F. Bertolini, F. Macchia and M. Pineschi, Org. Lett., 2009, 11, 3762-3765.

24 M. Pineschi, Synlett, 2014, 25, 1817-1826.

25 G. Palau-Lluch, X. Sanz, E. La Cascia, M. G. Civit, N. Miralles, A. B. Cuenca and E. Fernández, Pure Appl. Chem., 2015, 87, 181-193. 
26 X. Sanz, G. M. Lee, C. Pubill-Ulldemolins, A. Bonet, H. Gulyás, S. A. Westcott, C. Bo and E. Fernández, Org. Biomol. Chem., 2013, 11, 7004-7010.

27 S. Pietsch, E. C. Neeve, D. C. Apperley, R. Bertermann, F. Y. Mo, D. Qiu, M. S. Cheung, L. Dang, J. B. Wang, U. Radius, Z. Lin, C. Kleeberg and T. B. Marder, Chem.Eur. J., 2015, 21, 7082-7098.

28 L. Zhang, J. Cheng, B. Carry and Z. Hou, J. Am. Chem. Soc., 2012, 134, 14314-14317.

29 K. Semba, T. Fujihara, J. Terao and Y. Tsuji, Chem.-Eur. J., 2012, 18, 4179-4184.

30 A. Parra, L. Amenos, M. Guisan-Ceinos, A. López, J. L. García Ruano and M. Tortosa, J. Am. Chem. Soc., 2014, 136, 15833-15836.

31 Y. Q. Zhou, W. You, K. B. Smith and M. K. Brown, Angew. Chem., Int. Ed., 2014, 53, 3475-3479.

32 W. Su, T. J. Gong, X. Lu, M. Y. Xu, C. G. Yu, Z. Y. Xu, H. Z. Yu, B. Xiao and Y. Fu, Angew. Chem., Int. Ed., 2015, 54, 1295712961.

33 K. Takahashi, T. Ishiyama and N. Miyaura, Chem. Lett., 2000, 982-983.

34 K. Takahashi, T. Ishiyama and N. Miyaura, J. Organomet. Chem., 2001, 625, 47-53.

35 C. N. Welch and S. G. Shore, Inorg. Chem., 1968, 7, 225-230. 36 W. Biffar, H. Nöth, H. Pommerening and B. Wrackmeyer, Chem. Ber., 1980, 113, 333-341.

37 T. Ishiyama, M. Murata, T. A. Ahiko and N. Miyaura, Org. Synth., 2000, 77, 176-185.

38 P. Nguyen, G. Lesley, N. J. Taylor, T. B. Marder, N. L. Pickett, W. Clegg, M. R. J. Elsegood and N. C. Norman, Inorg. Chem., 1994, 33, 4623-4624.

39 P. Nguyen, R. B. Coapes, A. D. Woodward, N. J. Taylor, J. M. Burke, J. A. K. Howard and T. B. Marder, J. Organomet. Chem., 2002, 652, 77-85.

40 C. Zhong, S. Kunii, Y. Kosaka, M. Sawamura and H. Ito, J. Am. Chem. Soc., 2010, 132, 11440-11442.

41 S. Sebelius, V. J. Olsson and K. J. Szabó, J. Am. Chem. Soc., 2005, 127, 10478-10479.

42 F. G. Bordwell and X. M. Zhang, Acc. Chem. Res., 1993, 26, 510-517.

43 J. Kovac, J. Chem. Educ., 2012, 89, 1485-1486.

44 A. Wong, D. Laurencin, G. Wu, R. Dupree and M. E. Smith, J. Phys. Chem. A, 2008, 112, 9807-9813.

45 L. W. Mire, S. D. Wheeler, E. Wagenseller and D. S. Marynick, Inorg. Chem., 1998, 37, 3099-3106.

46 X. J. Qi, Y. Feng, L. Liu and Q. X. Guo, Chin. J. Chem., 2005, 23, 194-199.

47 X. Q. Yao, X. J. Hou, H. J. Jiao, H. W. Xiang and Y. W. Li, J. Phys. Chem. A, 2003, 107, 9991-9996.

48 Y. Feng, L. Liu, J. T. Wang, H. Huang and Q. X. Guo, J. Chem. Inf. Comput. Sci., 2003, 43, 2005-2013.

49 P. R. Rablen, J. Am. Chem. Soc., 1997, 119, 8350-8360.

50 J. Y. Wang, W. R. Zheng, L. L. Ding and Y. X. Wang, New J. Chem., 2017, 41, 1346-1362.

51 L. C. Ducati, N. Takagi and G. Frenking, J. Phys. Chem. A, 2009, 113, 11693-11698.

52 S. Sakaki and T. Kikuno, Inorg. Chem., 1997, 36, 226-229.
53 S. J. Blanksby and G. B. Ellison, Acc. Chem. Res., 2003, 36, 255-263.

54 Y. H. Cheng, X. Zhao, K. S. Song, L. Liu and Q. X. Guo, J. Org. Chem., 2002, 67, 6638-6645.

55 K. S. Song, L. Liu and Q. X. Guo, J. Org. Chem., 2003, 68, 262266.

56 M. J. Frisch, G. W. Trucks, H. B. Schlegel, G. E. Scuseria, M. A. Robb, J. R. Cheeseman, G. Scalmani, V. Barone, B. Mennucci, G. A. Petersson, H. Nakatsuji, M. Caricato, X. Li, H. P. Hratchian, A. F. Izmaylov, J. Bloino, G. Zheng, J. L. Sonnenberg, M. Hada, M. Ehara, K. Toyota, R. Fukuda, J. Hasegawa, M. Ishida, T. Nakajima, Y. Honda, O. Kitao, H. Nakai, T. Vreven, J. A. Montgomery Jr, J. E. Peralta, F. Ogliaro, M. Bearpark, J. J. Heyd, E. Brothers, K. N. Kudin, V. N. Staroverov, R. Kobayashi, J. Normand, K. Raghavachari, A. Rendell, J. C. Burant, S. S. Iyengar, J. Tomasi, M. Cossi, N. Rega, J. M. Millam, M. Klene, J. E. Knox, J. B. Cross, V. Bakken, C. Adamo, J. Jaramillo, R. Gomperts, R. E. Stratmann, O. Yazyev, A. J. Austin, R. Cammi, C. Pomelli, J. W. Ochterski, R. L. Martin, K. Morokuma, V. G. Zakrzewski, G. A. Voth, P. Salvador, J. J. Dannenberg, S. Dapprich, A. D. Daniels, O. Farkas, J. B. Foresman, J. V. Ortiz, J. Cioslowski and D. J. Fox, Gaussian 09 Revision A.1, Gaussian Inc., Wallingford CT, 2009.

57 L. A. Curtiss, K. Raghavachari, P. C. Redfern, V. Rassolov and J. A. Pople, J. Chem. Phys., 1998, 109, 7764-7776.

58 L. A. Curtiss, P. C. Redfern and K. Raghavachari, J. Chem. Phys., 2007, 126, 084108.

59 A. G. Baboul, L. A. Curtiss and P. C. Redfern, J. Chem. Phys., 1999, 110, 7650-7657.

60 Y. Fu, X. Y. Dong, Y. M. Wang, L. Liu and Q. X. Guo, Chin. J. Chem., 2005, 23, 474-482.

61 L. A. Curtiss, P. C. Redfern and K. Raghavachari, J. Chem. Phys., 2007, 127, 124105.

62 J. W. Ochterski, G. A. Petersson and K. B. Wiberg, J. Am. Chem. Soc., 1995, 117, 11299-11308.

63 A. D. Becke, J. Chem. Phys., 1993, 98, 5648-5652.

64 Y. Fu, Y. Mou, B. L. Lin, L. Liu and Q. X. Guo, J. Phys. Chem. A, 2002, 106, 12386-12392.

65 J. A. Montgomery Jr, M. J. Frisch, J. W. Ochterski and G. A. Petersson, J. Chem. Phys., 1999, 110, 2822-2827.

66 C. Lee, W. Yang and R. G. Parr, Phys. Rev. B: Condens. Matter Mater. Phys., 1988, 37, 785-789.

67 G. P. F. Wood, L. Radom, G. A. Petersson, E. C. Barnes, M. J. Frisch and J. A. Montgomery Jr, J. Chem. Phys., 2006, 125, 1-16.

68 Y. Zhao and D. G. Truhlar, J. Phys. Chem. A, 2006, 110, 13126-13130.

69 Y. Zhao, N. E. Schultz and D. G. Truhlar, J. Chem. Theory Comput., 2006, 2, 364-382.

70 J. D. Chai and M. Head-Gordon, J. Chem. Phys., 2008, 128, 084106.

71 R. Peverati and D. G. Truhlar, Phys. Chem. Chem. Phys., 2012, 14, 16187-16191.

72 A. D. Boese and J. M. L. Martin, J. Chem. Phys., 2004, 8, 3405-3442. 
73 R. Peverati and D. G. Truhlar, J. Chem. Phys., 2011, 135, 191102.

74 J. D. Chai and M. Head-Gordon, Phys. Chem. Chem. Phys., 2008, 10, 6615-6623.

75 Y. Zhao and D. G. Truhlar, Theor. Chem. Acc., 2008, 120, 215-241.

76 Y. Zhao and D. G. Truhlar, Theor. Chem. Acc., 2008, 41, 157167.

77 H. S. Rzepa, Org. Lett., 2005, 7, 4637-4639.

78 R. Peverati and D. G. Truhlar, Phys. Chem. Chem. Phys., 2012, 14, 13171-13174.

79 R. Peverati and D. G. Truhlar, J. Phys. Chem. Lett., 2011, 2, 2810-2817.

80 Y. Zhao and D. G. Truhlar, J. Phys. Chem. A, 2004, 108, 69086918.

81 J. Yang and M. P. Waller, J. Phys. Chem. A, 2013, 117, 174182.

82 J. P. Perdew, K. Burke and Y. Wang, Phys. Rev. B: Condens. Matter Mater. Phys., 1996, 54, 16533-16539.

83 R. Peverati and D. G. Truhlar, J. Chem. Theory Comput., 2012, 8, 2310-2319.

84 J. P. Perdew, Phys. Rev. B: Condens. Matter Mater. Phys., 1986, 33, 8822-8824.

85 S. Grimme, J. Antony, S. Ehrlich and H. Krieg, J. Chem. Phys., 2010, 132, 154104.

86 Y. Zhao, N. E. Schultz and D. G. Truhlar, J. Chem. Phys., 2005, 123, 161103.

87 Y. Zhao and D. G. Truhlar, J. Chem. Phys., 2006, 125, 194101.

88 T. Yanai, D. P. Tew and N. C. Handy, Chem. Phys. Lett., 2004, 393, 51-57.

89 M. Ernzerhof and G. E. Scuseria, J. Chem. Phys., 1999, 110, 5029-5036.

90 R. Peverati, Y. Zhao and D. G. Truhlar, J. Phys. Chem. Lett., 2011, 2, 1991-1997.

91 B. J. Lynch, P. L. Fast, M. Harris and D. G. Truhlar, J. Phys. Chem. A, 2000, 104, 4811-4815.

92 R. Peverati and D. G. Truhlar, J. Phys. Chem. Lett., 2012, 3, 117-124.

93 S. Grimme, J. Comput. Chem., 2006, 27, 1787-1799.

94 Y. Fu, L. Liu, H. Z. Yu, Y. M. Wang and Q. X. Guo, J. Am. Chem. Soc., 2005, 127, 7227-7234.

95 B. Lambie, R. Ramaekers and G. Maes, J. Phys. Chem. A, 2004, 108, 10426-10433.

96 A. Modelli, L. Mussoni and D. Fabbri, J. Phys. Chem. A, 2006, 110, 6482-6486.

97 Y. Jiang, H. Yu, Y. Fu and L. Liu, Sci. China: Chem., 2015, 58, 673-683.

98 A. D. Becke, Phys. Rev. A: At., Mol., Opt. Phys., 1988, 38, 3098-3100.

99 J. A. Pople, M. Head-Gordon, D. J. Fox, K. Raghavachari and L. A. Curtiss, J. Chem. Phys., 1989, 90, 5622-5629.
100 L. A. Curtiss, K. Raghavachari, G. W. Trucks and J. A. Pople, J. Chem. Phys., 1991, 94, 7221-7230.

$101 \mathrm{~J}$. W. Ochterski, G. A. Petersson and J. A. Montgomery Jr, J. Chem. Phys., 1996, 104, 2598-2619.

102 G. P. F. Wood, L. Radom, G. A. Petersson, E. C. Barnes, M. J. Frisch and J. A. Montgomery Jr, J. Chem. Phys., 2006, 125, 094106.

103 L. L. Ding, W. R. Zheng and Y. X. Wang, New J. Chem., 2015, 39, 6935-6943.

104 Y. X. Wang and W. R. Zheng, J. Sulfur Chem., 2015, 36, 155159.

105 Y. Feng, L. Liu, J. T. Wang, S. W. Zhao and Q. X. Guo, J. Org. Chem., 2004, 69, 3129-3138.

106 A. K. Chandra, P. C. Nam and M. T. Nguyen, J. Phys. Chem. A, 2003, 107, 9182-9188.

107 W. R. Zheng, W. X. Xu, Y. X. Wang and Z. C. Chen, Comput. Theor. Chem., 2014, 1027, 116-124.

108 W. R. Zheng, Z. L. Guo, Z. C. Chen, Q. Yang and T. Huang, Res. Chem. Intermed., 2012, 38, 1791-1806.

109 M. Arrowsmith, J. Böhnke, H. Braunschweig, A. Deißenberger, R. D. Dewhurst, W. C. Ewing, C. Hörl, J. Mies and J. H. Muessig, Chem. Commun., 2017, 53, 8265-8267.

110 I. Demachy and F. Volatron, J. Phys. Chem., 1994, 98, 1072810734.

111 J. Shi, X. Y. Huang, J. P. Wang and R. Li, J. Phys. Chem. A, 2010, 114, 6263-6272.

112 Y. D. Wu and D. W. K. Lai, J. Org. Chem., 1996, 61, 79047910.

113 Y. M. Wang, C. Zhou, Y. Fu, L. Liu and Q. X. Guo, Chin. J. Org. Chem., 2005, 25, 1398-1402.

114 J. Takaya and N. Iwasawa, ACS Catal., 2012, 2, 1993-2006.

115 V. M. Dembitsky, H. A. Ali and M. Srebnik, Advances in Organometallic Chemistry, Academic Press, Cambridge, 2004, pp. 193-250.

116 S. A. Westcott and E. Fernández, Advances in Organometallic Chemistry, Academic Press, Cambridge, 2015, pp. 39-89.

117 R. Barbeyron, E. Benedetti, J. Cossy, J. J. Vasseur, S. Arseniyadis and M. Smietana, Tetrahedron, 2014, 70, 8431-8452.

118 T. Ishiyama, N. Matsuda, M. Murata, F. Ozawa, A. Suzuki and N. Miyaura, Organometallics, 1996, 15, 713-720.

119 D. S. Laitar, P. Mueller and J. P. Sadighi, J. Am. Chem. Soc., 2005, 127, 17196-17197.

120 D. S. Laitar, E. Y. Tsui and J. P. Sadighi, J. Am. Chem. Soc., 2006, 128, 11036-11037.

121 V. Lillo, M. R. Fructos, J. Ramírez, A. A. C. Braga, F. Maseras, M. M. Díaz-Requejo, P. J. Perez and E. Fernández, Chem.-Eur. J, 2007, 13, 2614-2621. 